Plutonium Metal and Oxide Container

Weld Development and Qualification

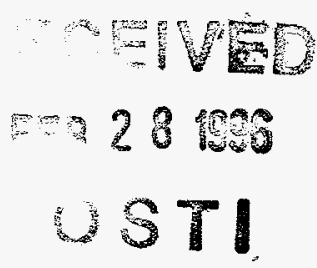

Rudolph Fernandez

David R. Horrell

Carl W. Hoth

Stanley W. Pierce

Nora A. Rink

Yvonne M. Rivera

Vicente D. Sandoval

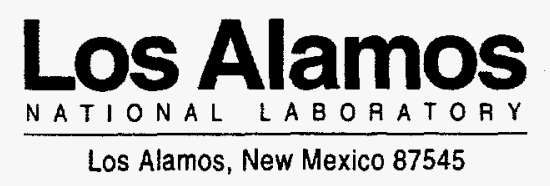

DARBOUTON OF THS DOCUMENT IS UNMMES W" 



\section{DISCLAIMER}

This report was prepared as an account of work sponsored by an agency of the United States Government. Neither the United States Government nor any agency thereof, nor any of their employees, makes any warranty, express or implied, or assumes any legal liability or responsibility for the accuracy, completeness, or usefulness of any information, apparatus, product, or process disclosed, or represents that its use would not infringe privately owned rights. Reference herein to any specific commercial product, process, or service by trade name, trademark, manufacturer, or otherwise does not necessarily constitute or imply its endorsement, recommendation, or favoring by the United States Government or any agency thereof. The views and opinions of authors expressed herein do not necessarily state or reflect those of the United States Government or any agency thereof. 



\title{
PLUTONIUM METAL AND OXIDE CONTAINER \\ WELD DEVELOPMENT AND QUALIFICATION
}

\author{
By
}

Rudolph Fernandez, David R. Horrell, Carl W. Hoth,

Stanley W. Pierce, Nora A. Rink, Yvonne M. Rivera, and Vicente D. Sandoval

\begin{abstract}
Welds were qualified for a container system to be used for long-term storage of plutonium metal and oxide. Inner and outer containers are formed of standard tubing with stamped end pieces gas-tungsten-arc (GTA) welded onto both ends. The weld qualification identified GTA parameters to produce a robust weld that meets the requirements of the Department of Energy standard DOE-STD-3013-94, "Criteria for the Safe Storage of Plutonium Metals and Oxides."
\end{abstract}




\section{INTRODUCTION}

In response to the Department of Energy (DOE) initiatives to place excess nuclear material inventories in safe long-term storage awaiting final disposition, the Los Alamos National Laboratory has instituted a quality-assured packaging project to accomplish this goal for its materials. This report describes the development and qualification of the GTA welding process used in joining the end pieces onto tubing to form the containers for plutonium metal and oxide storage to meet the requirements of DOE-STD-3013-94 $4^{(1)}$. A program was established to develop and qualify the equipment, fixtures, and weld parameters to ensure adequate and consistent weld penetration. The intent of the development process was to hold constant as many welding variables as feasible and to characterize the remaining major process variables. It was demonstrated through a statistical experimental method that variations in the major process settings of two times the estimated magnitude expected during production would produce acceptable leak-tight welds. These welds were of adequate size to meet burst-pressure and drop-testing requirements. The development and qualification data characterize the effect of process variables on measurable weld dimensions and burst strength and serve as a baseline for production process quality monitoring.

\section{DESIGN AND REQUIREMENTS}

\section{The Container}

The container system consists of an inner welded container nested within an outer welded container as shown in Fig. 1. As shown in Figs. 2 and 3, the inner and outer containers are made of 0.065-in.-thick, type 304 stainless welded tubing, $4.5 \mathrm{in}$. in diameter by $9.35 \mathrm{in}$. long and $5.0 \mathrm{in}$. in diameter by $10.0 \mathrm{in}$. long, respectively. The end pieces are stamped from 0.065-in.-thick, type 304 stainless 


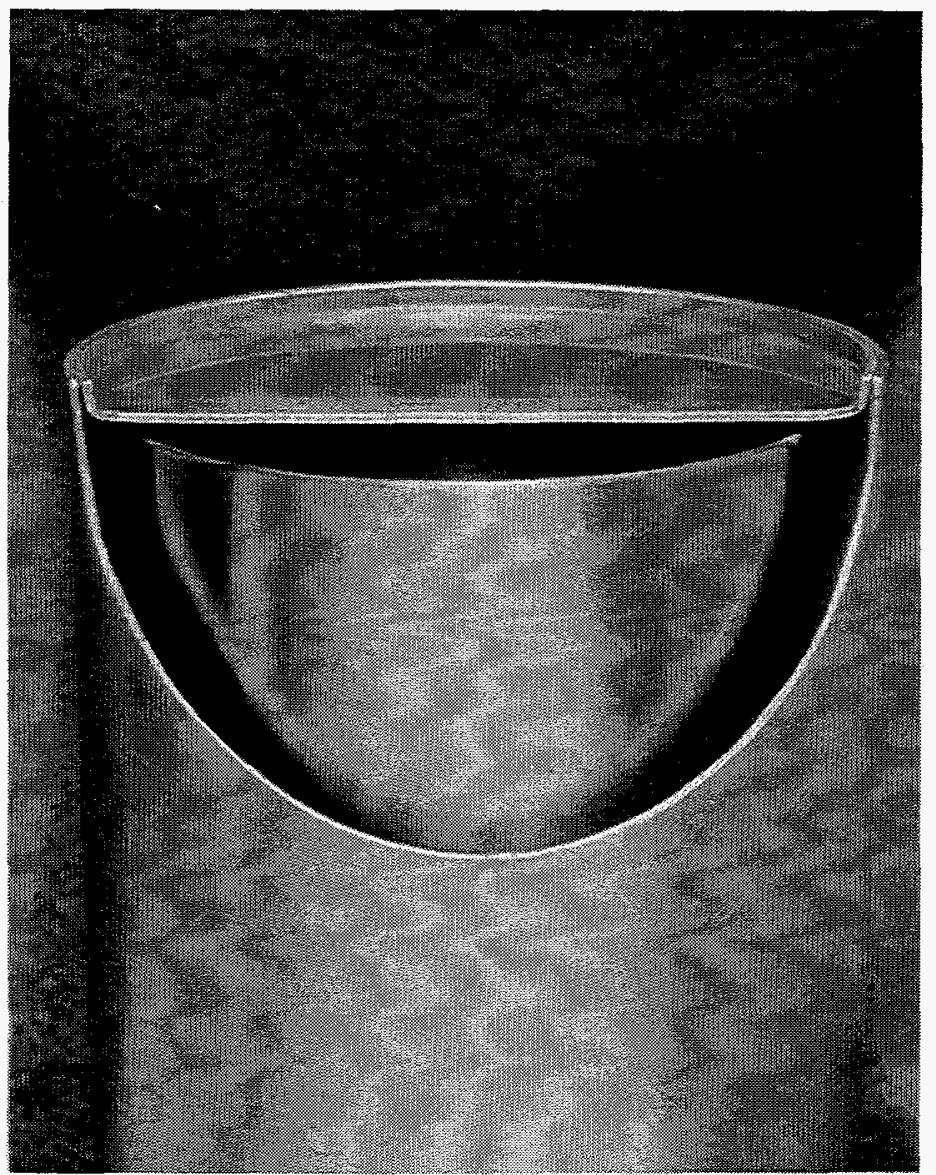

Fig. 1. Double container system with the outer container cut away to show the inner container. The cutaway section shows the edge joint between the end piece and the tubing before welding. Photo reduction $0.65 \mathrm{X}$.

steel sheet. Thickness tolerances are \pm 0.005 in. for all parts. The end pieces have a 0.250 -in. raised lip around the circumference, which, when press-fit inside and flush with the end of the container, provides an edge joint for autogenous GTA welding. The end pieces were fabricated to ensure a light press-fit into the container. Reference drawing number $26 \mathrm{Y}-203051^{(2)}$. 


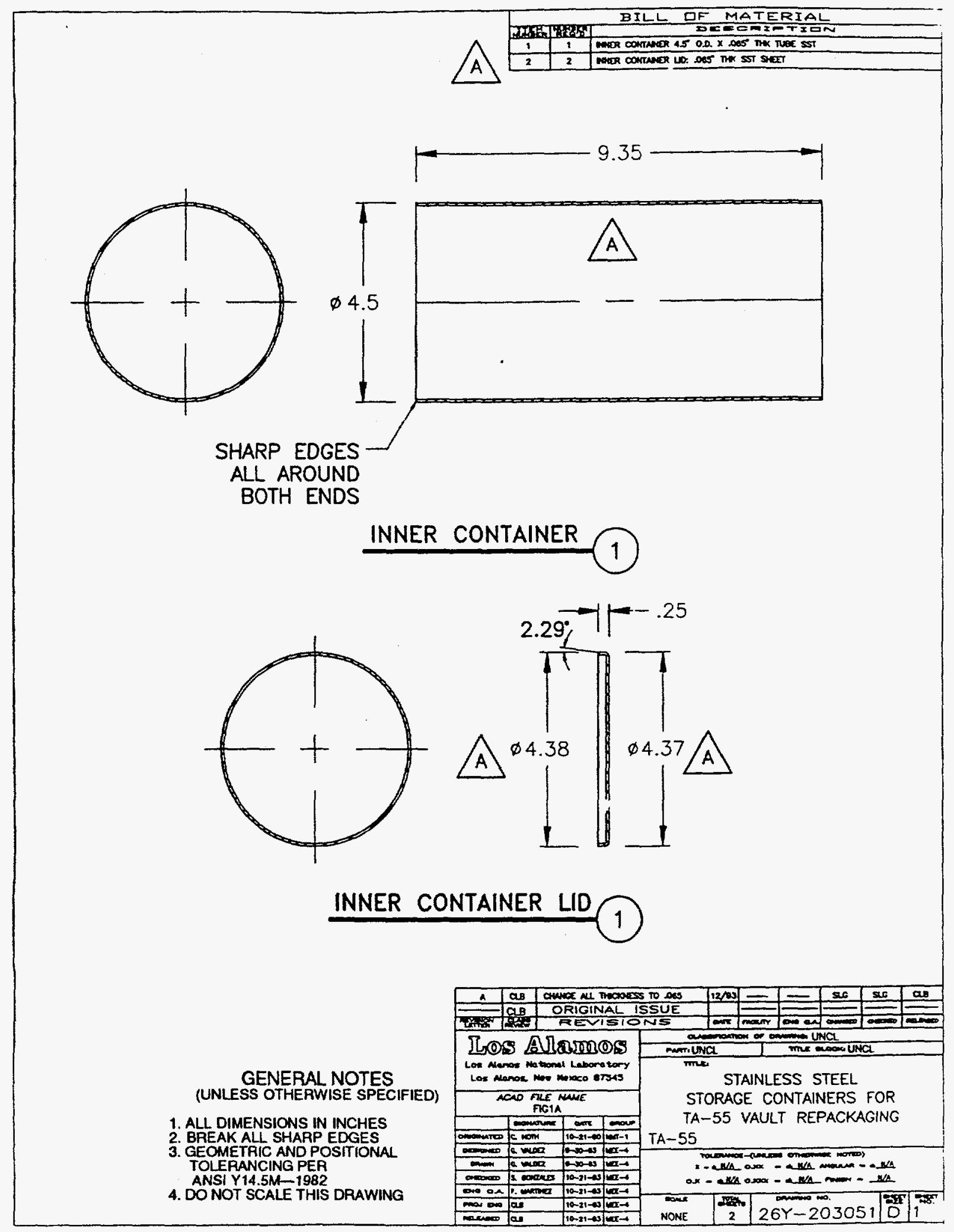

Fig. 2. Dimensioned drawing of the inner container tube and end piece. 


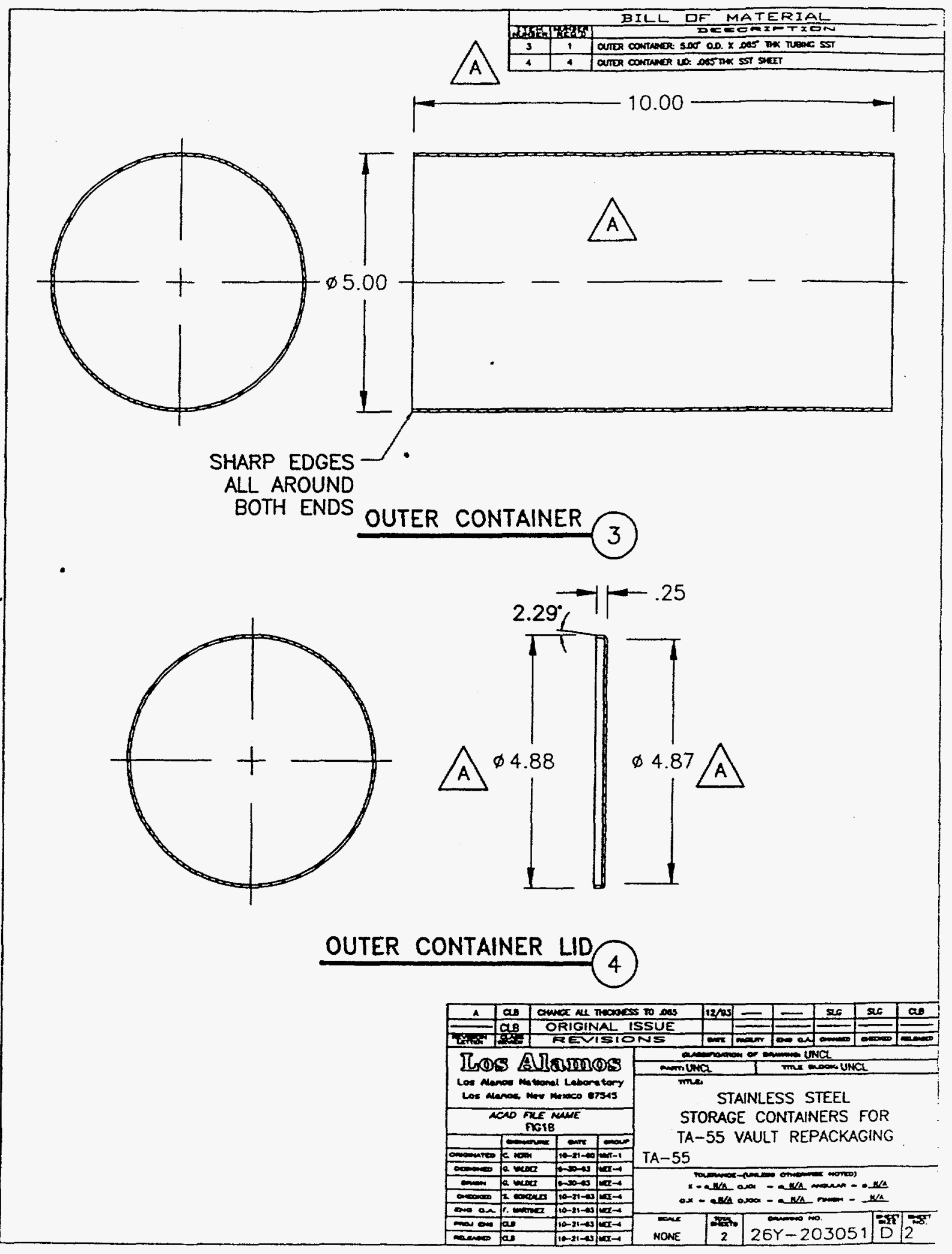

Fig. 3. Dimensioned drawing of the outer container tube and end piece. 


\section{Material Chemistry}

The inner container tubing, outer container tubing, and end pieces were made from single respective heat lots of material, and, therefore, weld penetration variation caused by heat-to-heat chemistry variations is not a factor within this lot of components. If additional components from different heat lots are to be welded, test welds must be made to confirm that use of different heats has no significant detrimental effect on weld size. If changes in the welding process parameters are required, the new process must be qualified.

Table I lists the material chemistry for the container components. The sulfur (S) content of the components affects the GTA weld shape through thermocapillary convection, which is the flow of molten metal in the weld pool driven by gradients in surface tension. Surface tension is temperature- and chemistrydependent. The difference in temperature between the center and weld pool edge creates a surface tension gradient and convective flow. The presence or absence of surface-active elements such as sulfur and oxygen affects the value of surface tension at a given temperature. A low-sulfur stainless steel has higher surface tension at the low-temperature edge of the weld pool than at the center, and, therefore, convective heat transfer is outward from the pool center, resulting in a wide, shallow weld profile. For a high-sulfur weld, the surface tension gradient and fluid flow are reversed, and the resultant weld is deep and narrow. For a weld joint composed of components of differing sulfur levels, the weld fluid flow is toward the low-sulfur component, and the resultant weld is offset from the joint and deeper on the low-sulfur side. Figure 4 illustrates typical GTA weld cross-sectional profiles and the responsible thermocapillary convection pattern. For the present container system, the end pieces have a low sulfur content, 15 to 17 parts per million (ppm), and the tubing sulfur content is relatively high, 120 to $190 \mathrm{ppm}$. This dissimilar sulfur condition required that 
the GTA welding electrode be biased toward the high-sulfur side of the weld joint in an effort to center the weld penetration and promote a uniform weld profile.

TABLE I. Typical Chemical Analysis of Container Components

Material Chemistry Analysis

$(w t \%)$

End Piece diam

Tubing o.d.

\begin{tabular}{|c|c|c|c|c|c|c|}
\hline Element & 4.5 in. & $5.0 \mathrm{in}$. & \multicolumn{2}{|c|}{4.5 in. } & \multicolumn{2}{|c|}{5 in. } \\
\hline$\overline{\mathrm{Fe}-56}$ & $\overline{71.0000}$ & $\overline{71.7000}$ & 70.1000 & 70.2000 & 70.6000 & 70.3000 \\
\hline B & 0.0013 & 0.0010 & 0.0000 & 0.0000 & 0.0000 & 0.0001 \\
\hline C & 0.0460 & 0.0450 & 0.0190 & 0.0210 & 0.0550 & 0.0600 \\
\hline $\mathrm{Si}-28$ & 0.3590 & 0.3500 & 0.5090 & 0.5170 & 0.4530 & 0.4720 \\
\hline $\mathbf{P}$ & 0.0350 & 0.0350 & 0.0430 & 0.0410 & 0.0400 & 0.0420 \\
\hline $\mathrm{s}$ & 0.0015 & 0.0017 & 0.0173 & 0.0187 & 0.0120 & 0.0128 \\
\hline Ti -48 & 0.0010 & 0.0012 & 0.0035 & 0.0035 & 0.0009 & 0.0010 \\
\hline V & 0.0780 & 0.0740 & 0.0480 & 0.0490 & 0.0510 & 0.0530 \\
\hline Cr-52 & 17.6000 & 17.2000 & 17.4000 & 17.2000 & 17.9000 & 17.4000 \\
\hline $\mathrm{Mn}$ & 1.6600 & 1.6100 & 1.7200 & 1.7400 & 1.4200 & 1.4600 \\
\hline Co & 0.1000 & 0.0970 & 0.1920 & 0.1950 & 0.1820 & 0.1990 \\
\hline $\mathrm{Ni}-60$ & 8.5700 & 8.4000 & 9.5200 & 9.6400 & 8.7800 & 9.4300 \\
\hline $\mathrm{Cu}-63$ & 0.1840 & 0.1770 & 0.2040 & 0.2050 & 0.2670 & 0.2780 \\
\hline $\mathrm{Zr}-90$ & 0.0040 & 0.0037 & 0.0034 & 0.0033 & 0.0027 & 0.0030 \\
\hline Mo-100 & 0.3740 & 0.3340 & 0.2570 & 0.2430 & 0.2360 & 0.2340 \\
\hline Sn-118 & 0.0082 & 0.0081 & 0.0099 & 0.0103 & 0.0119 & 0.0120 \\
\hline
\end{tabular}




\section{Weld Setup and Equipment}

The welding setup used for process development and qualification established the production welding setup for the inner and outer containers. The setup and welding procedure is detailed in 604-NMT4 ${ }^{(3)}$.

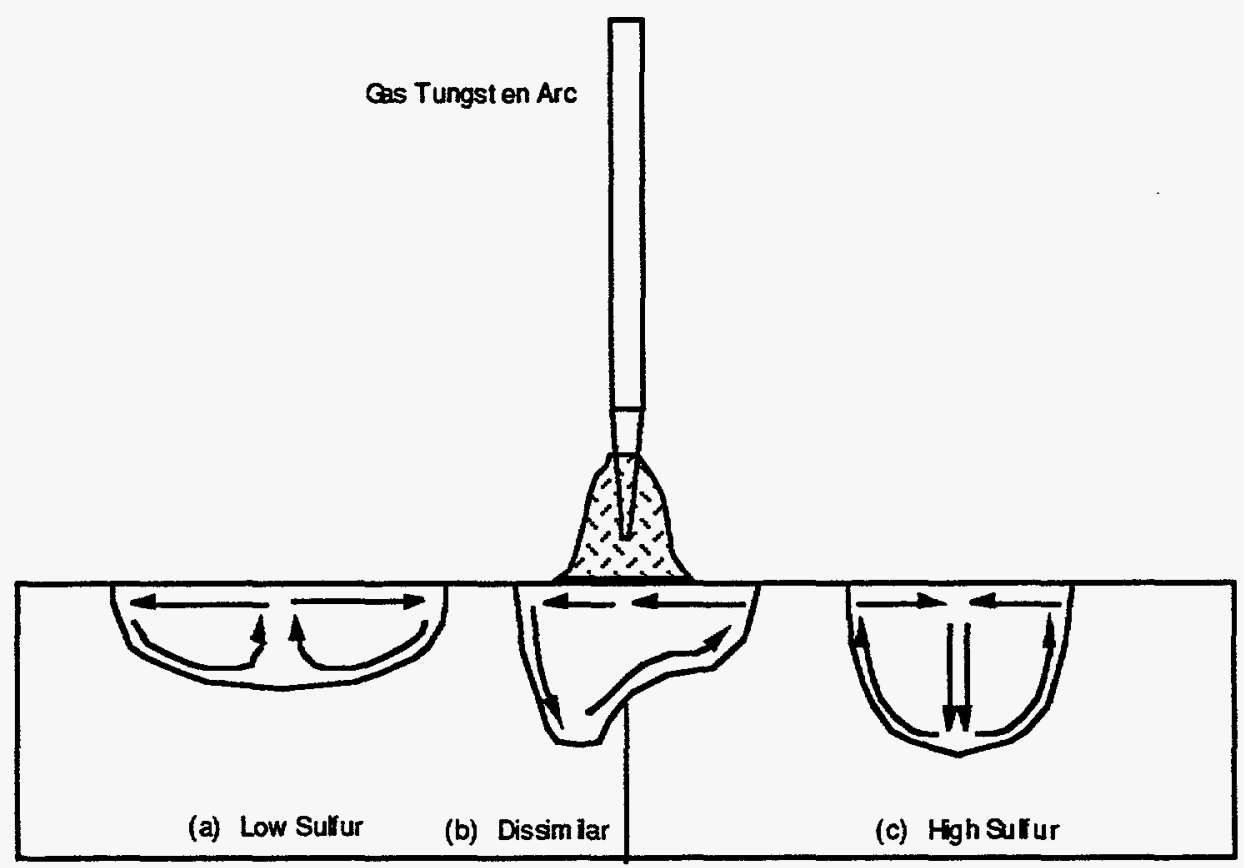

Fig. 4. Schematic representation of GTA weld, thermocapillary flow patterns, and the associated typical weld cross-sectional profiles for: (a) a lowsulfur base metal, (b) a dissimilar joint between low- and high-sulfur base metals, and (c) a high-sulfur base metal.

End Piece Pressing. The end piece is pressed in flush with the end of the container using a 1000-lb manually operated Arbor press fitted with a 0.5-in.thick by 5.5 -in.-diam stainless steel pressing disk and a stainless steel base plate. 
Tack Welding. Before it is welded, the end piece is tack welded to the container to prevent it from lifting as a result of uneven thermal expansion during welding. Sixteen tack welds are evenly spaced around the weld joint using an alternating sequence. With the first tack weld at the $0^{\circ}$ position, the tacking sequence continues through $180^{\circ}, 90^{\circ}$, and $270^{\circ}$ positions. The remaining tack welds are interspersed within the quadrants established by the first four tack welds.

Rotation Fixture. The container tubing is positioned in a vertical orientation rotated beneath a fixed-position GTA torch. The rotation fixture is a Jetline model ZB-200B turntable retrofitted with a ten-turn potentiometer control. The speed range on the turntable is from 0 to $3 \mathrm{rpm}$. The rotation fixture, welding cables, and connections are electrically insulated from the welding chamber to ensure a single ground path during welding.

Arc Gap. The GTA torch is fixed along the vertical axis, and the tungsten-towork distance (arc gap) for each weld is manually set to 0.050 in., using a feeler gauge. For the first end-piece weld, the container sits squarely on the unwelded, machined end, and the inherent variation in arc gap is negligible. For the second end-piece weld, however, the container sits on the nonuniform surface of the first welded end, and it must be manually adjusted within the three-jaw chucks to ensure consistent arc gap. Process improvement plans include a fixture base designed such that the container sits on the uniform portion of the end piece.

Cross-Seam Torch Location. The welding torch is mounted in a spring-loaded, torch-tracker device. The tracker utilizes a wheel positioned just below the weld to follow the outside surface of the container and ensure that the tungsten-toweld joint distance along the horizontal axis remains constant during the weld. The tracker accommodates for out-of-round conditions caused by uneven thermal expansion as the weld progresses. 
Figure 5 is a photograph of the container and weld fixture in position for a weld. As shown in Fig. 6, the electrode is positioned approximately $0.020 \mathrm{in}$. off the centerline of the joint, toward the outside of the container, in an effort to compensate for nonsymmetrical heat flow resulting from the dissimilar sulfur contents of the components. The first weld pass tends to roll to the inside, forming a rounded bead around the inside edge of the end piece. Weld

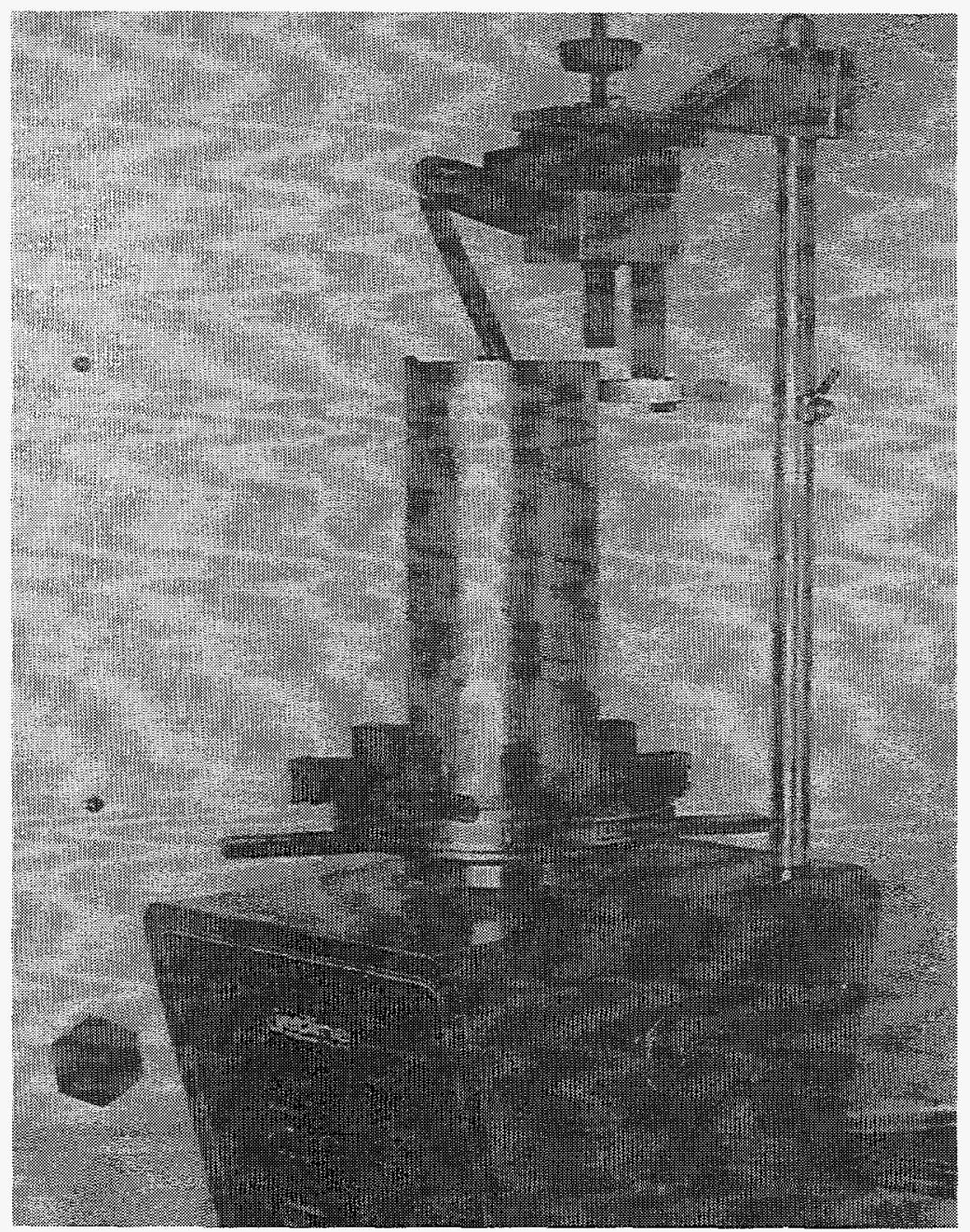

Fig. 5. The container and weld fixture in position for a weld. 


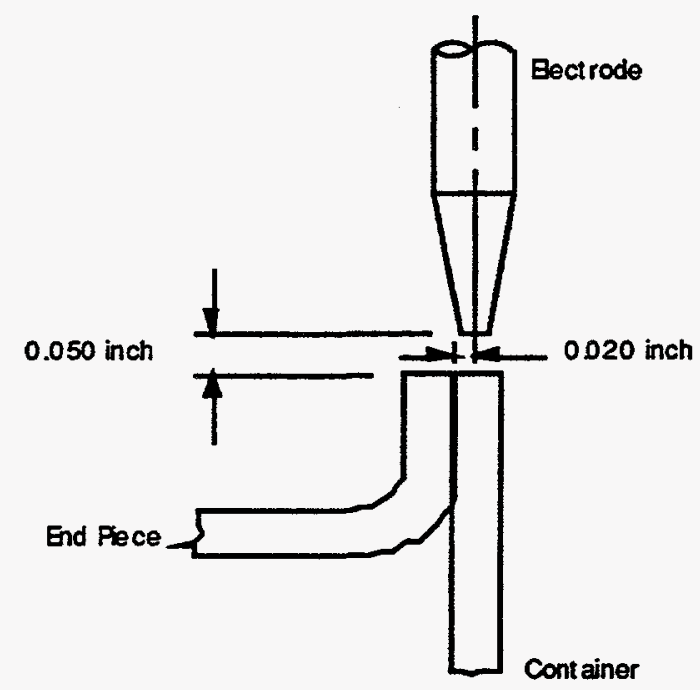

Fig. 6. Schematic of the electrode position offset 0.020 inch to the outside of the joint centerline.

shrinkage in the first pass reduces the container diameter at the joint causing the relative position of the electrode to shift toward the outside edge. With this torch position, melting of the second weld pass tends to favor the outside edge, which contributes to the uniformity of the completed weld.

Welder and Torch. The welding equipment used in development consists of an L-Tec type H-306-HF, 300-A power supply equipped with an auxiliary Wavetek model CDM-600 digital induction ammeter and an L-Tec model HW-26 gas-cooled GTA torch. The welding electrode is 0.094 -in.-diam, $2 \%$ thoriated tungsten. The electrode tip is prepared with a $10^{\circ}$ included angle and a 0.030 -in.diam flat.

Welding Atmosphere. Welding is performed inside a helium atmosphere glovebox. The helium atmosphere provides the dry, inert atmosphere required both for welding and for protection of the stored materials. Additionally, the helium atmosphere within the storage container allows for leak detection. Oxygen content in the chamber is monitored with a Teledyne model 317-RB, 
trace oxygen analyzer and was held to below $50 \mathrm{ppm}$ during welding. At this oxygen level, the completed weld and adjacent area are generally shiny.

A dark, sooty residue is generated during welding and is deposited on the surface of the container and surrounding weld fixtures. The residue was analyzed with Auger spectroscopy and was identified as manganese oxide. The source of the residue is the type 304 stainless steel, which contains approximately $2 \%$ manganese by weight. Manganese is readily vaporized in the welding arc and combines with residual oxygen in the glovebox. An additional source of oxygen may be the various oxides contained within the steel that decompose in the weld pool.

Component Cleaning. Before they are welded, the containers and end pieces are cleaned according to procedure $600-\mathrm{NMT} 4^{(4)}$. The cleaning includes immersion in an ultrasonically agitated aqueous solution, followed by a water rinse, an alkaline soak, another water rinse, and a nitric acid soak. The components are subsequently blow-dried with dried filtered air. After they are cleaned, the components are handled with white cotton gloves and are individually wrapped in oil-free aluminum foil.

\section{Qualification Basis}

Qualification of the welding process was based on the results of process characterization, burst tests, and drop tests. The welding process was characterized by measuring and evaluating the effects of different weld-current and travel-speed settings on weld size and burst strength.

Proof-of-Development (POD). Burst tests and weld size measurements were done on containers from a POD matrix. A nominal weld setting was developed by test welds to provide a robust weld such that some deviation to lower heat could be tolerated while maintaining $100 \%$ weld penetration, defined as equal to 
the wall thickness. The POD was established by purposely varying the welding current and travel speed about the nominal settings by up to two times the normal variation expected in production welding. Weld current and travel speed are the two process settings that may vary enough in production to significantly affect weld size. The normal variation expected in production weld settings was estimated to be approximately $5 \mathrm{~A}$ and 3 seconds per revolution. With the present system, both current and travel speed are manually set by means of potentiometer dials, and, therefore, reproducing the exact levels from one weld to the next is not possible. Other important process variables such as arc gap and cross-seam electrode location are well controlled and repeatable and were therefore omitted from the statistical experimental design. Welds made at the extremes of the normal variation are called production extremes. Welds made at two times the normal variation are called development extremes. The POD matrix is shown graphically in Fig. 7.

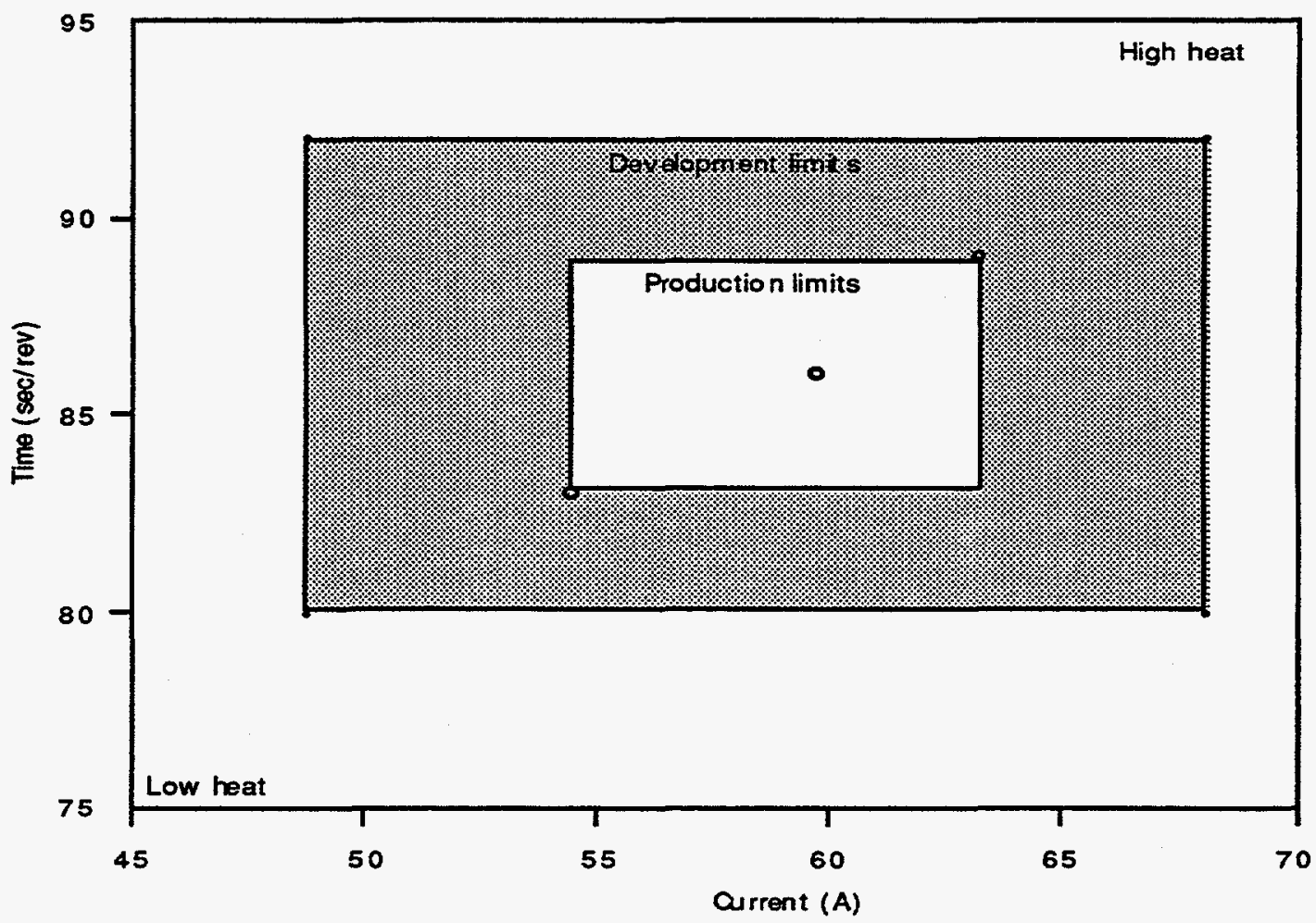

Fig. 7. Schematic representation of the POD matrix. 
Weld-Size Characterization. The qualification included metallographic measurement of the POD welds. The weld-size data were correlated with the process parameter settings and the burst test results, establishing a benchmark for use in evaluation of weld quality and process stability. Figure 8 is a schematic representation of a weld cross section and the three measurements of weld size. The inside weld size and the outside weld size are defined as the maximum dimension of the weld measured perpendicular to the weld joint interface from the respective side of the container. The center weld size is the maximum dimension of the weld as measured along the axis of the weld joint interface.

Burst Testing. The qualification required acceptable burst test results from three containers; one welded at the high-heat development extreme (high current/low

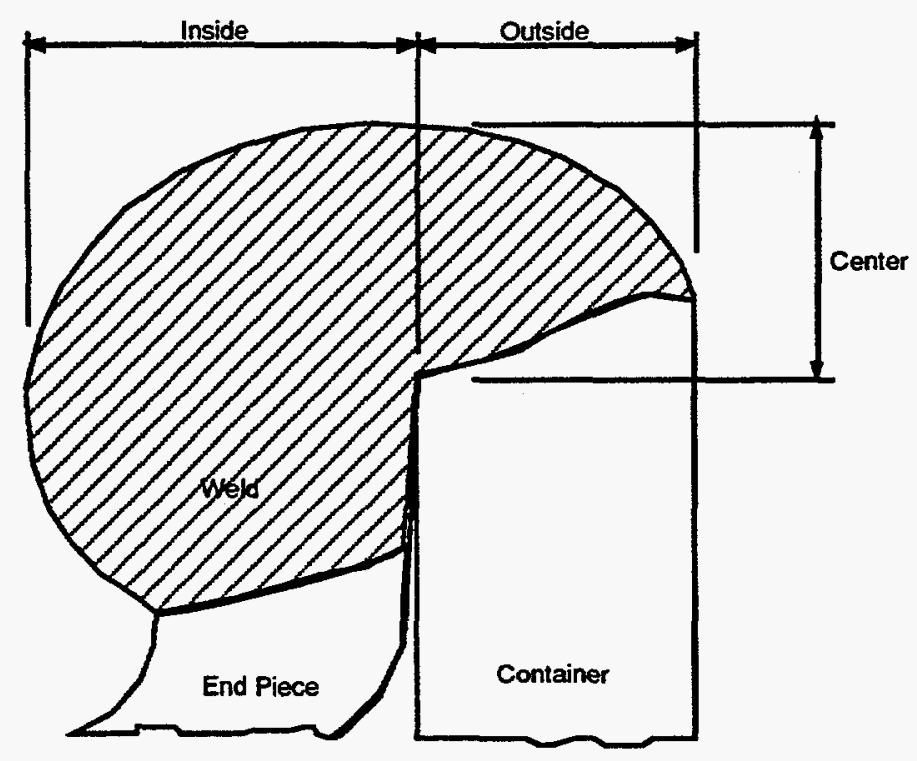

Fig. 8. A schematic of a weld cross section and three weld size measurements.

travel speed), one welded at the nominal parameter set, and one welded at the lowheat development extreme (low current/high speed). The minimum acceptable burst pressure as calculated for the worst-case expectations of plutonium load and moisture content at the $150 \%$ safety factor required by DOE-STD $3013-94$ is $450 \mathrm{psi}^{\left({ }^{(1)}\right.}$. 
Drop Testing. Drop testing was performed on a complete inner and outer container system. The inner container was filled with $10 \mathrm{lb}$ of scrap tool steel. All container welds were made at the nominal setting to be used in production. Six drop tests were done from a height of $8 \mathrm{ft}$, three onto a flat surface and three onto the edge of a 3-in. by 3-in. steel angle. For the two impact surfaces, the container was dropped in three orientations: with the container vertical, impacting squarely on the container end; with the container horizontal, impacting on the side of the container; and with the container at 45 degrees to the vertical axis, impacting on the welded edge of the container. Immediately after each drop, the container system was helium leak-tested. Following completion of all drop tests, the outer container was drilled and vented of helium, and the inner container was then leak-tested.

\section{RESULTS \& DISCUSSION}

\section{Weld Profile}

Figures 9(a) through 9(n) are photomicrographs of the welds from the POD matrix. Welds are displayed in order according to the relative heat input, starting with the development low-extreme. Despite offsetting the electrode to the outside of joint, the welds have a nonuniform profile attributed to the fluid flow associated with the dissimilar sulfur content of the components. The welds have a pronounced, rounded bead on the inside edge of the joint, and no measurable buildup of material on the outside dimension. The melting on the inside of the welds extended further down the edge than it did along the center joint line, or along the outside edge.

As shown later, the burst strength of the present weld is excellent. A more uniformly shaped weld, however, with outer-edge melting and reinforcement comparable to the edge is esthetically desirable and may further raise burst 

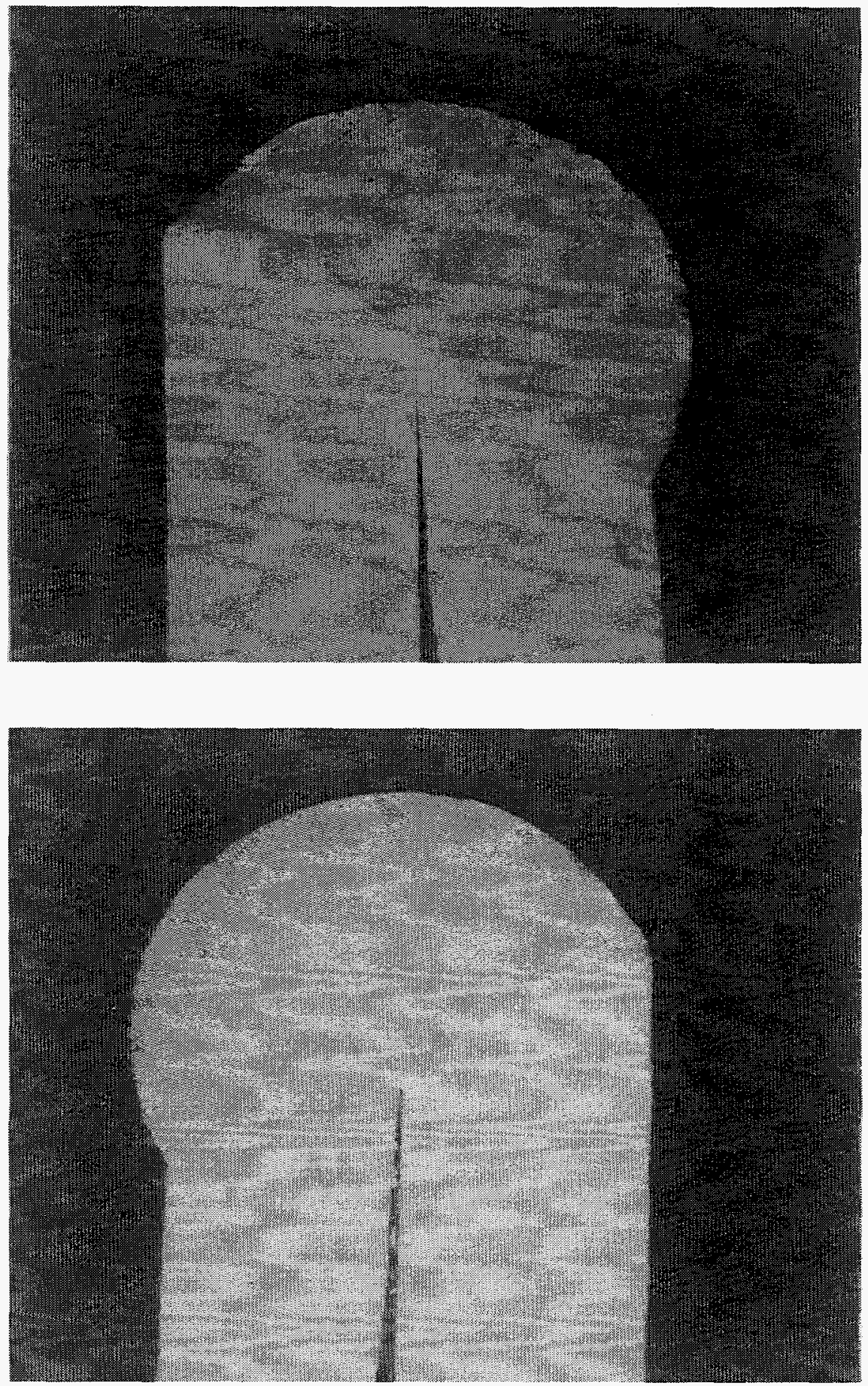

Figs. 9a (above) and 9b. Weld 51T, development low extreme, cross sections taken from the weld start (9a) and $180^{\circ}$ from the weld start (9b) (20X). 

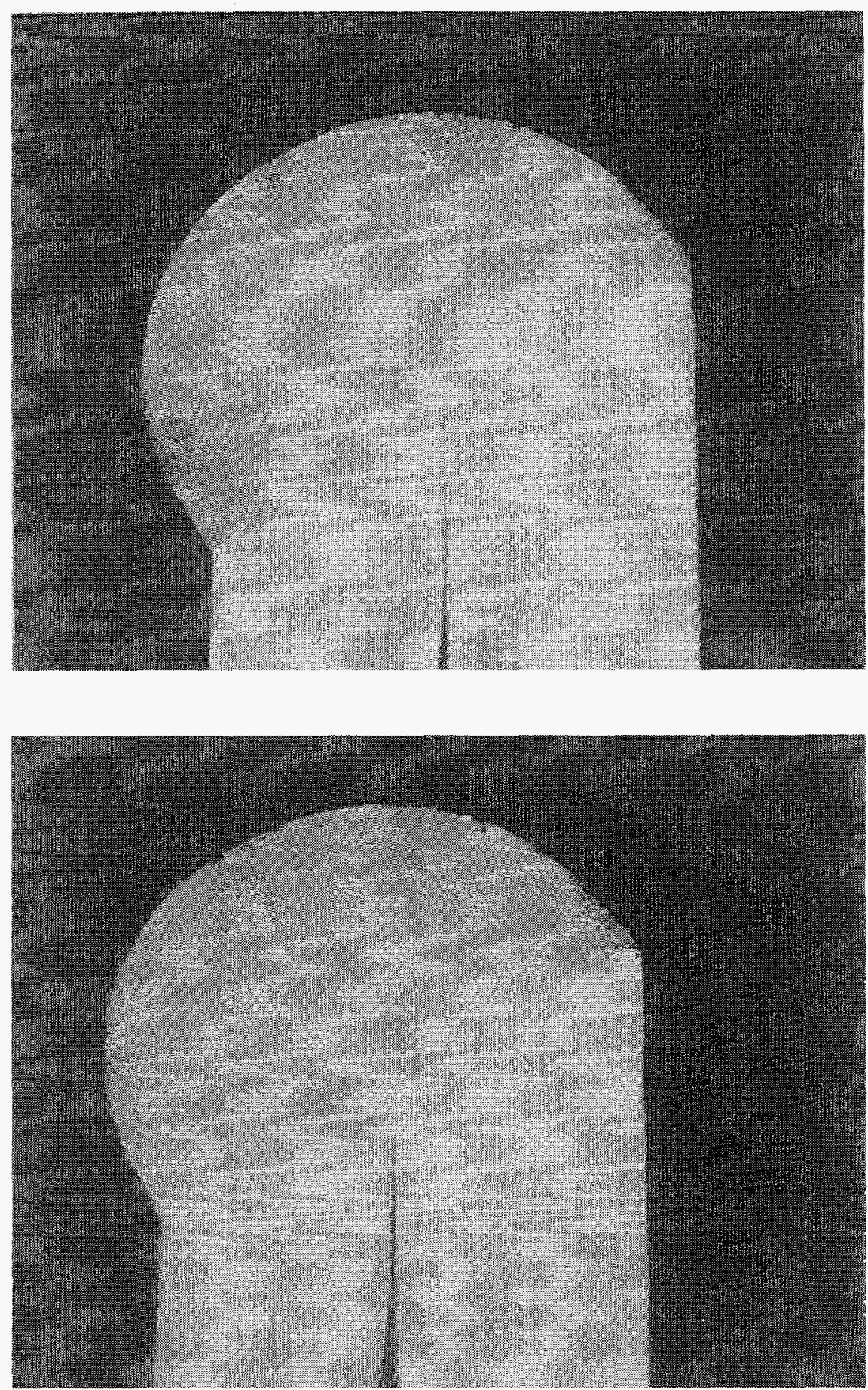

Figs. 9c (above) and 9d. Weld 51B, statistical combination, cross sections taken from the weld start (9c) and $180^{\circ}$ from the weld start (9d) (20X). 

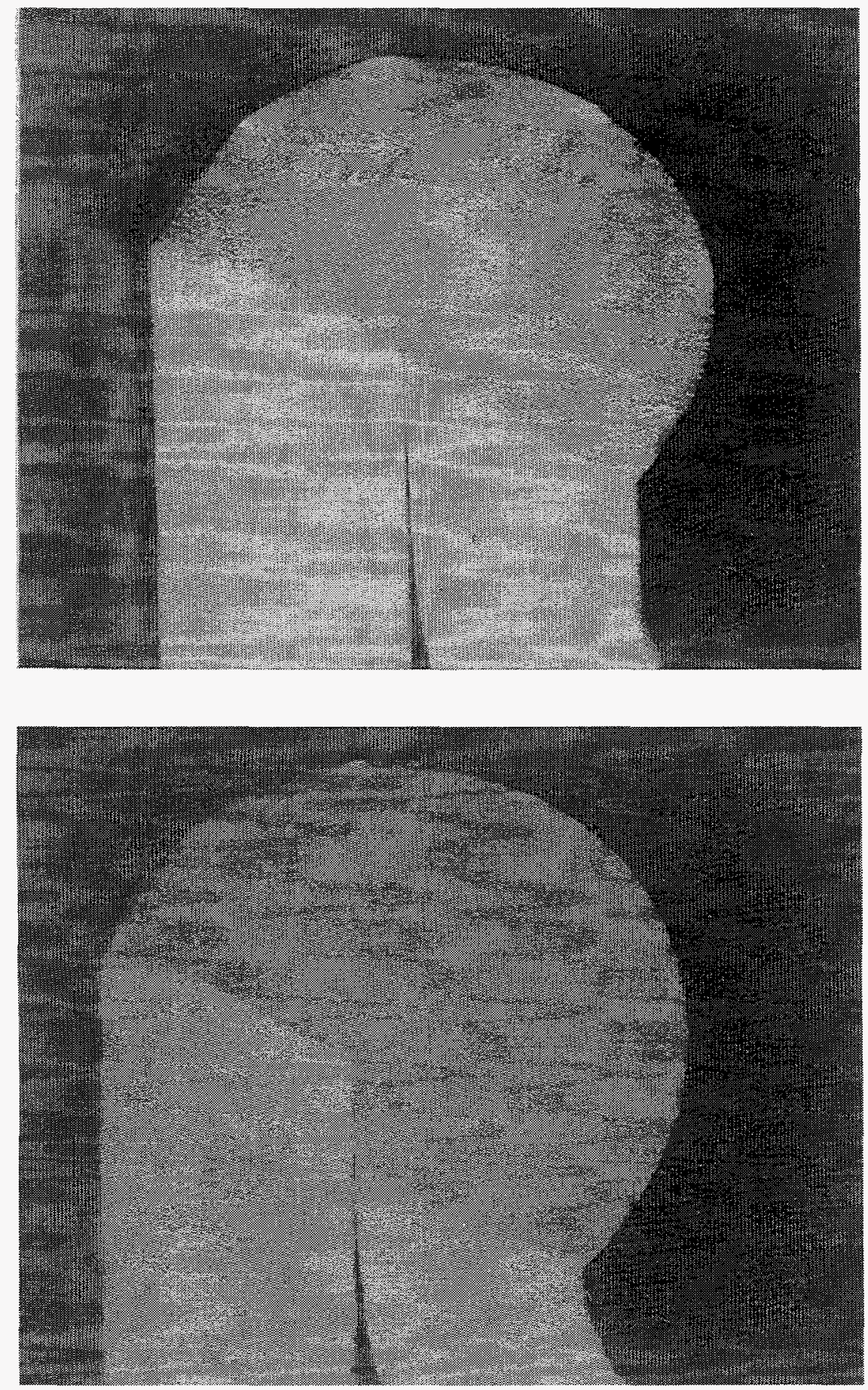

Figs. 9e (above) and 9f. Weld $48 \mathrm{~T}$, production low extreme, cross sections taken from the weld start (9e) and $180^{\circ}$ from the weld start (9f) (20X). 

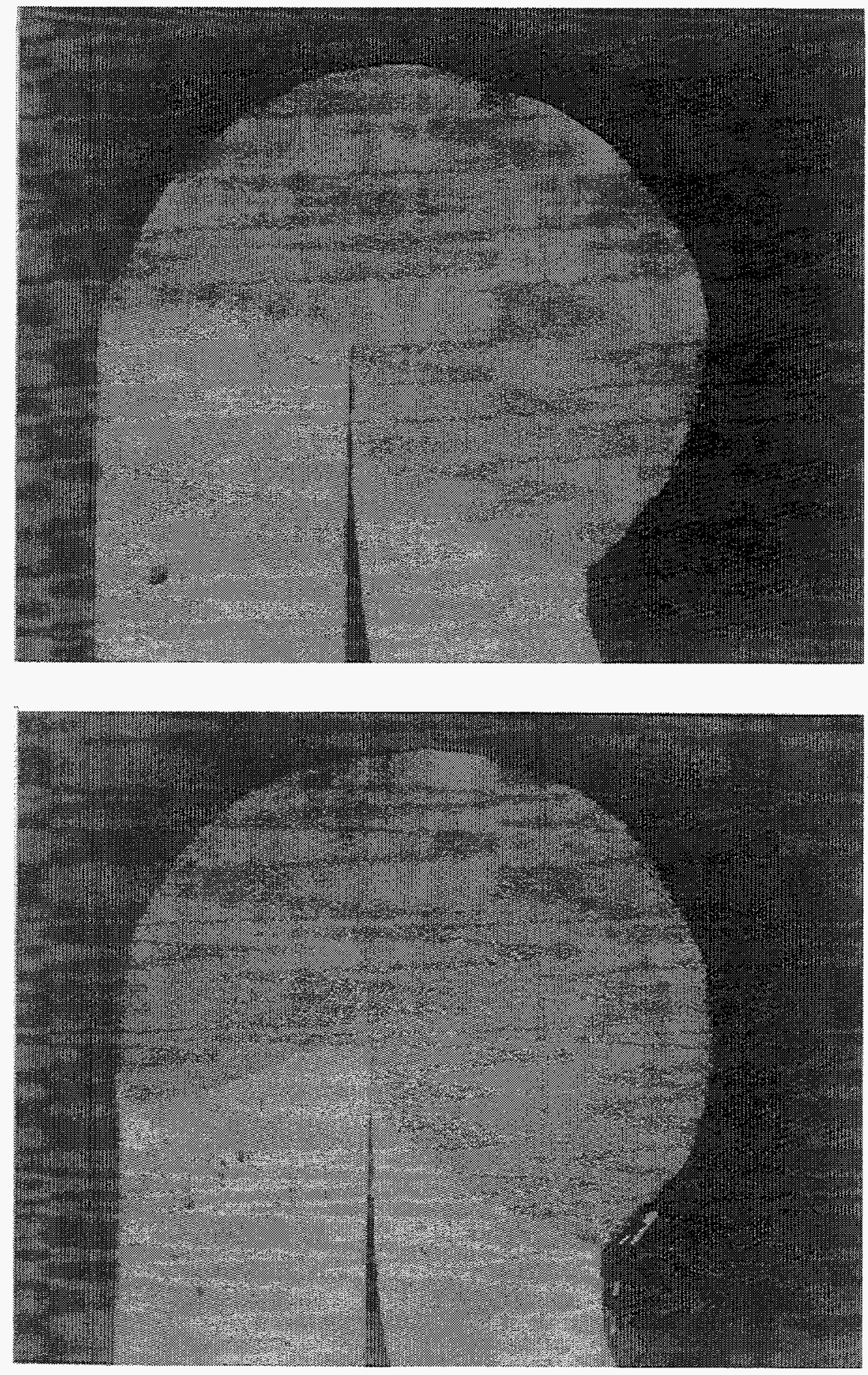

Figs. 9g (above) and 9h. Weld 48B, nominal, cross sections taken from the weld start $(9 \mathrm{~g})$ and $180^{\circ}$ from the weld start (9h) (20X). 

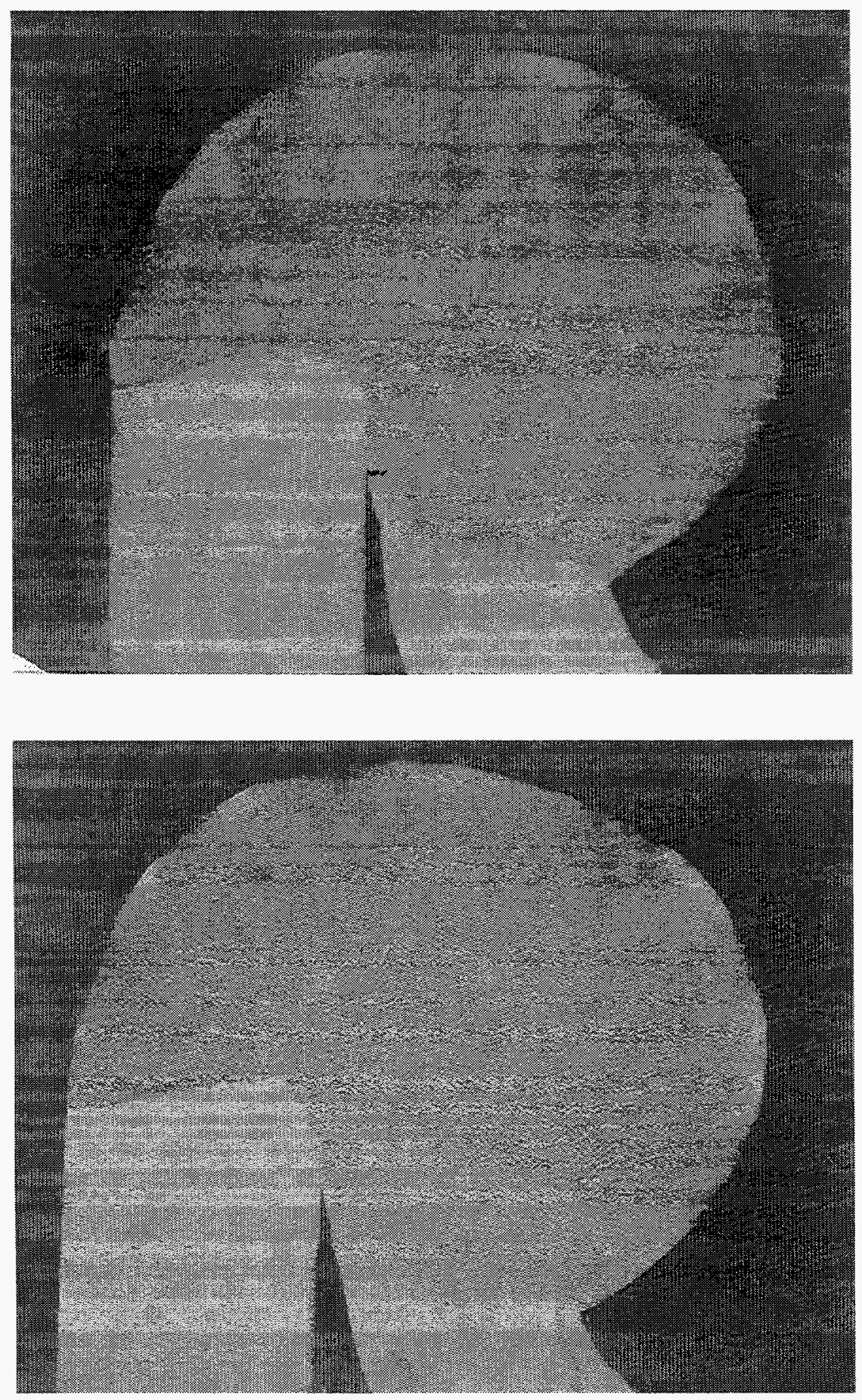

Figs. 9i (above) and 9j. Weld 47T, production high extreme, cross sections taken from the weld start (9i) and $180^{\circ}$ from the weld start (9j) (20X). 

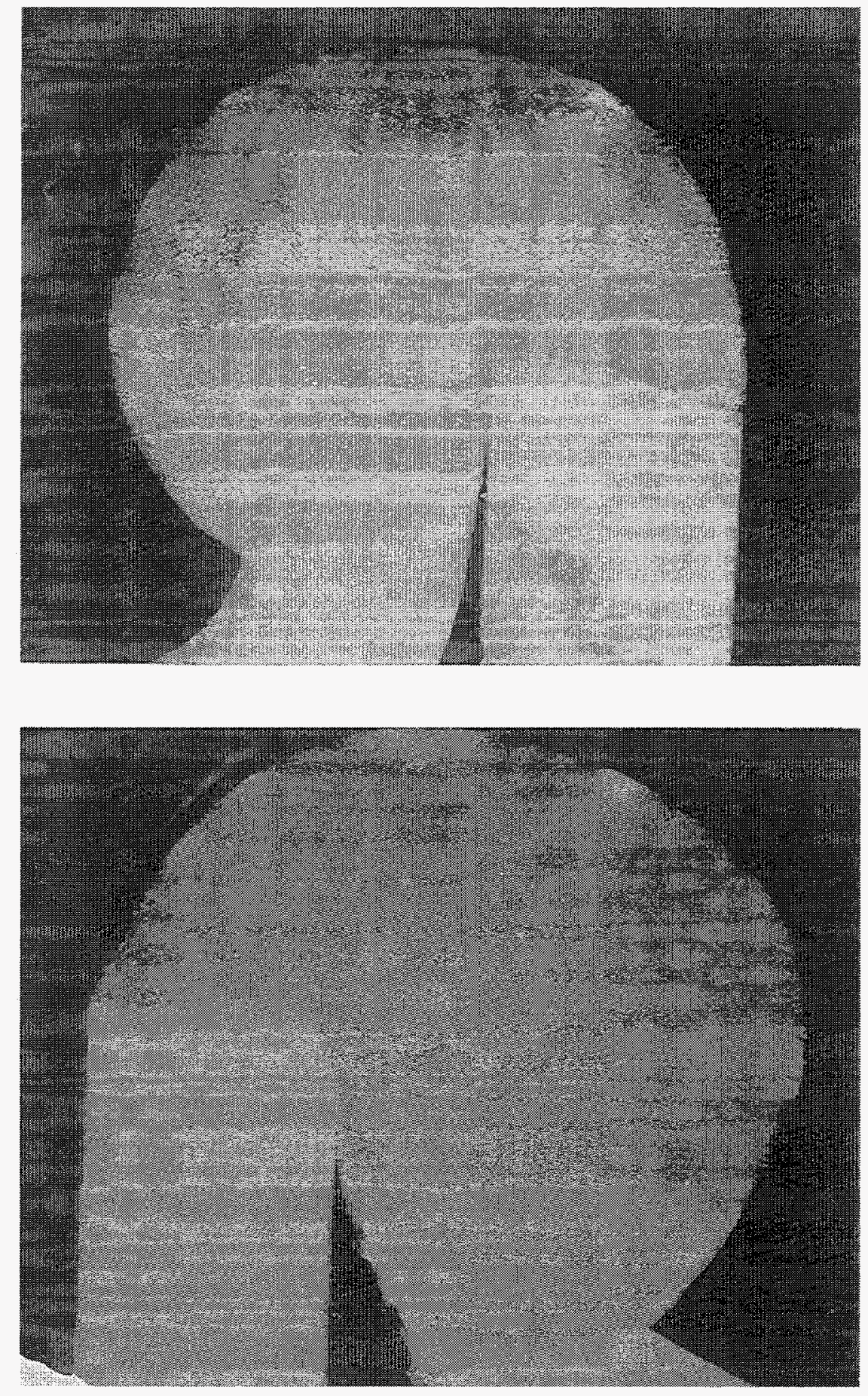

Figs. 9k (above) and 9l. Weld 50T, statistical combination, cross sections taken from the weld start (9k) and $180^{\circ}$ from the weld start (9l) (20X). 

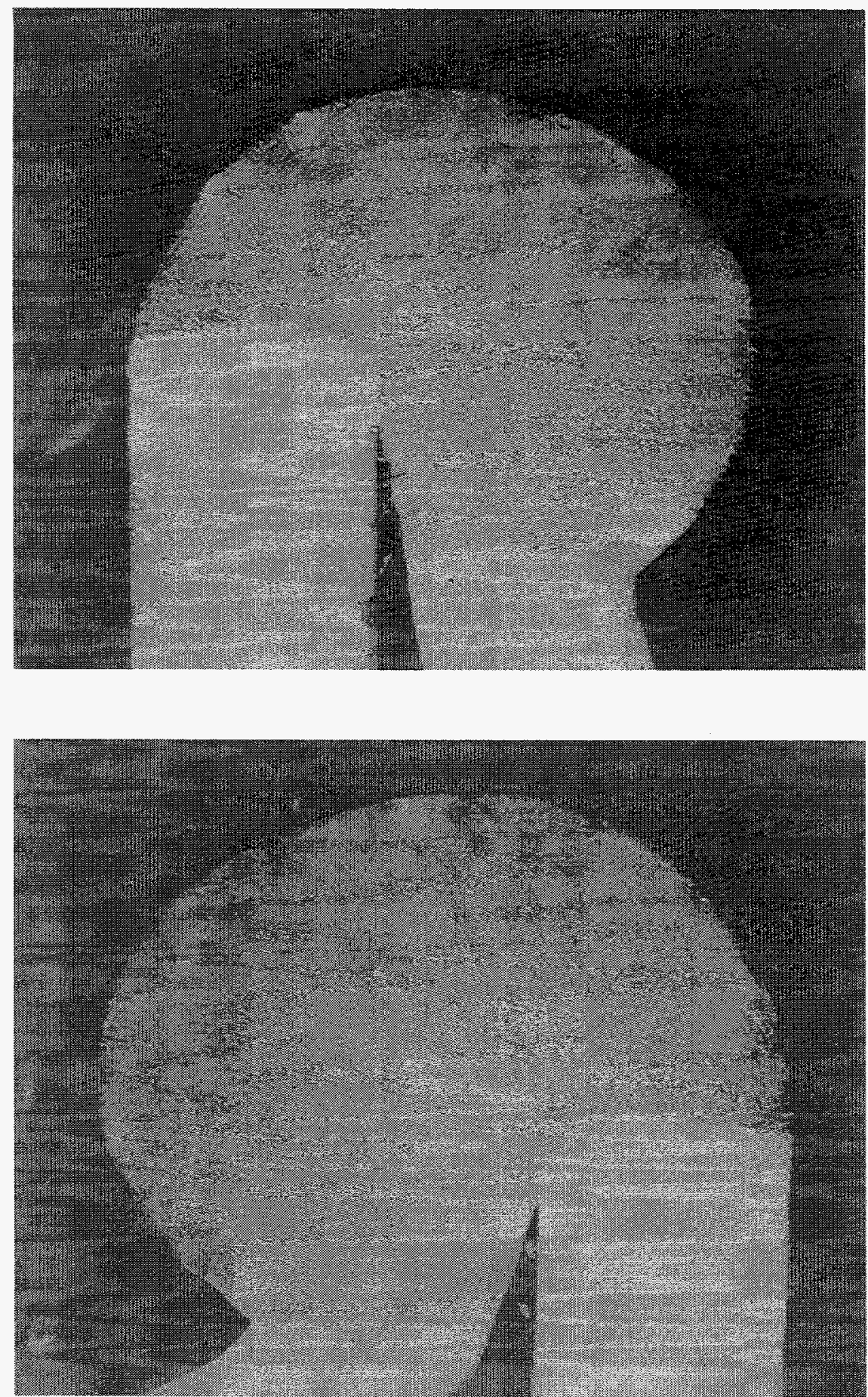

Figs. 9m (above) and 9n. Weld 50B, development high extreme, cross sections taken from the weld start $(9 \mathrm{~m})$ and $180^{\circ}$ from the weld start $(9 \mathrm{n})(20 \mathrm{X})$. 


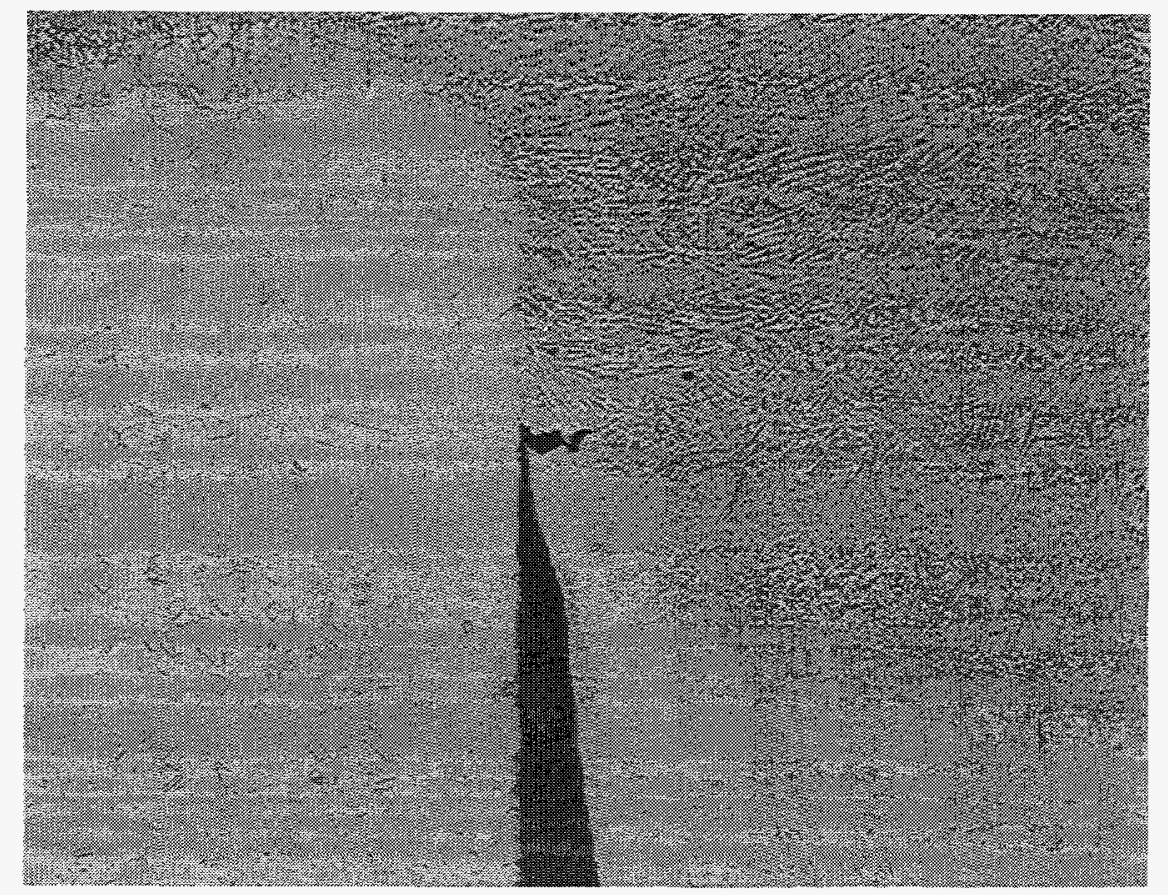

Fig. 10. Microfissure in weld 47T, production high extreme (50X).

strength. A consistent degree of melting at the weld center, relative to the inner and outer edges, is desirable so that the extent of internal melting can be judged based on external observation. Future process improvements aimed at achieving a uniform weld profile may involve repositioning and/or tilting the electrode, using pulsed current, and/or using arc oscillation. The development and production high-extreme welds each exhibited a microfissure approximately 0.005 -in. long located in the end piece just above the inside weld fusion zone. The fissures extend perpendicular from the joint centerline toward the inside edge. Figure 10 shows the microfissure in weld number $47 \mathrm{~T}$, the production high-heat extreme, at a magnification of approximately 50X. The fissures appear to be associated with excessive melting of the end piece. Considering the small size of the fissures, the occurrence of fissures only at the high-heat extreme, and the substantial burst strength demonstrated by high-heat extreme units, it does not seem likely that they are a serious detriment to container integrity. Process improvements aimed at reducing heat input, reducing process variation, and refinement of the weld profile will aid in avoiding the occurrence of fissures. 


\section{Weld Size Characterization}

Measurements of the POD welds were taken from metallographic samples at the weld start and 180 degrees from the start. Table II lists the POD weld-size results.

TABLE II. Proof of Development Weld Size Matrix

Weld Size

Weld Heat (a)

Fig. No. Weld No. Location Inside Center Outside Rotation Current Parameter Type (deg) (in.) (in.) (in.) (sec/rev) (A)

\begin{tabular}{|c|c|c|c|c|c|c|c|c|}
\hline $9 a$ & $50 \mathrm{~T}$ & 0 & 0.100 & 0.084 & 0.065 & 80 & 68 & Statistical \\
\hline \multirow[t]{2}{*}{$9 b$} & $50 \mathrm{~T}$ & 180 & 0.120 & 0.103 & 0.065 & 80 & 68 & Statistical \\
\hline & Average & & 0.110 & 0.094 & 0.065 & & & \\
\hline$\overline{9 c}$ & $51 \mathrm{~T}$ & 0 & 0.070 & 0.076 & 0.065 & 80 & 49 & Dev Low \\
\hline \multirow[t]{2}{*}{$9 d$} & $51 \mathrm{~T}$ & 180 & 0.071 & 0.062 & 0.065 & 80 & 49 & Dev Low \\
\hline & Average & & 0.070 & 0.069 & 0.065 & & & \\
\hline $9 e$ & $50 \mathrm{~B}$ & 0 & 0.114 & 0.105 & 0.065 & 92 & 68 & Dev High \\
\hline \multirow[t]{2}{*}{$9 f$} & $50 \mathrm{~B}$ & 180 & 0.096 & 0.075 & 0.065 & 92 & 68 & Dev High \\
\hline & Average & & 0.105 & 0.090 & 0.065 & & & \\
\hline $9 \mathrm{~g}$ & $\overline{51 B}$ & 0 & 0.078 & 0.071 & 0.065 & 92 & 49 & Statistical \\
\hline \multirow[t]{2}{*}{$9 h$} & $51 B$ & 180 & 0.074 & 0.076 & 0.065 & 92 & 49 & Statistical \\
\hline & Average & & 0.076 & 0.073 & 0.065 & & & \\
\hline $9 i$ & $48 \mathrm{~B}$ & 0 & 0.091 & 0.073 & 0.065 & 86 & 60 & Nominal \\
\hline \multirow[t]{2}{*}{$9 j$} & 48B & 180 & 0.088 & 0.077 & 0.065 & 86 & 60 & Nominal \\
\hline & Average & & 0.090 & 0.075 & 0.065 & & & \\
\hline $9 \mathrm{k}$ & $48 \mathrm{~T}$ & $\overline{0}$ & 0.080 & 0.075 & 0.065 & 83 & 54 & Prod Low \\
\hline \multirow[t]{2}{*}{91} & $48 \mathrm{~T}$ & 180 & 0.085 & 0.075 & 0.065 & 83 & 54 & Prod Low \\
\hline & Average & & 0.083 & 0.075 & 0.065 & & & \\
\hline $9 \mathrm{~m}$ & $47 \mathrm{~T}$ & 0 & 0.105 & 0.090 & 0.065 & 89 & 63 & Prod High \\
\hline \multirow[t]{2}{*}{$9 n$} & $47 \mathrm{~T}$ & 180 & 0.112 & 0.099 & 0.065 & 89 & 63 & Prod High \\
\hline & Average & & 0.109 & 0.094 & 0.065 & & & \\
\hline
\end{tabular}

(a) These development welds were made on the 5-in.-diam outer container. 
Analysis of current and travel speed effects on weld dimensions revealed that travel speed variation, within the range investigated, was insignificant. The changes in weld dimensions associated with travel speed were minor in comparison to the changes attributable to the weld current, and to variation from unknown sources.

For this study, current was the primary controlling factor for the weld dimensions. As current is increased, there is a resultant linear increase in both the inside and center weld dimensions. Regression models for the average inside and center dimensions yielded correlation coefficients $\left(R^{2}\right)$, of 0.923 and 0.794 respectively. The $R^{2}$ value of 0.923 indicates that $92.3 \%$ of the variance in the inside weld dimension is attributable to the changes in weld current. The root mean square error (RMSE) for the inside and center dimension models was 0.0049 and 0.0053 respectively. The RMSE represents an estimate of the uncertainty about predictions made with the model and provides a means of calculating the lower and upper $95 \%$ confidence levels about a predicted value of weld size. The lower and upper $95 \%$ confidence levels are generated by applying a factor of 2.5 times the RMSE to the predicted weld size for a given current. An estimated $95 \%$ of the welds made at the given parameter setting should fall within this confidence range of weld size. The linear models that describe the effect of current on average weld size are given in Eqs. (1) and (2) and are graphically represented in Fig. 11.

$$
\begin{aligned}
& \text { Inside Weld Size }(\text { inch })=-0.01858+0.00188 \times \text { Current } \\
& \left(R^{2}=0.923, \mathrm{RMSE}=0.0049\right)
\end{aligned}
$$$$
\text { Center Weld Size }(\text { inch })=-0.01389+0.00115 \times \text { Current }
$$
$\left(\mathrm{R}^{2}=0.0 .794, \mathrm{RMSE}=0.0053\right)$ 


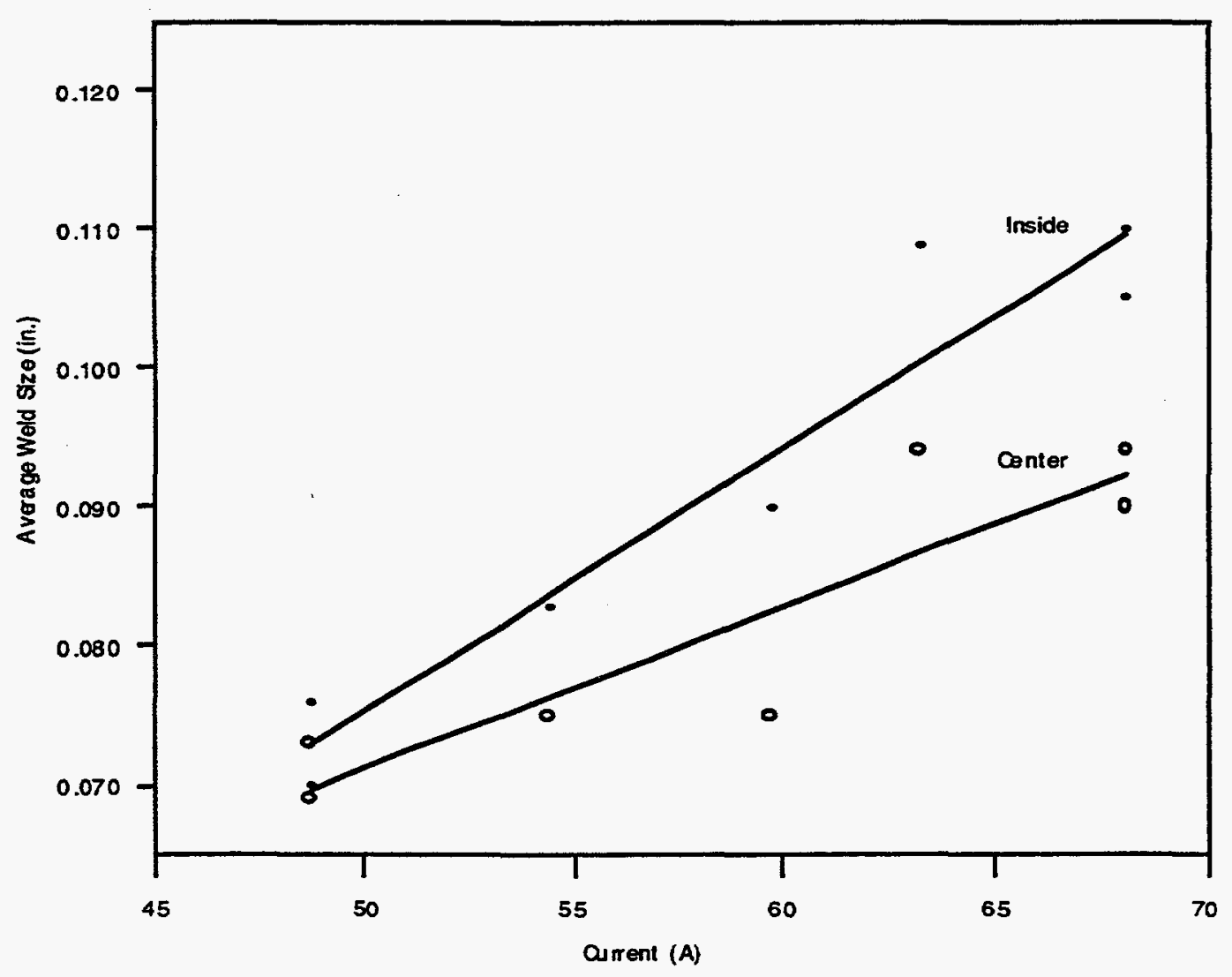

Fig. 11. Average weld size as a function of current.

\section{Burst Tests}

Three 4.5-in.-diam inner (material) containers were fabricated for burst testing: one with nominal parameter welds on both ends, one with a development high and a production high weld, and one with a development low and a production low weld. Table III shows the weld parameters for each of these containers. Note that time of rotation is proportional for the two sizes of containers shown in Table II and Table III. As illustrated in Fig. 12, burst strength increased as a function of increased heat input to the weld, i.e., increased current and time per revolution. All three containers burst well above the minimum acceptable level of 450 psi. For the high burst unit, the production high weld ruptured at 2096 psi, 
TABLE III. Burst Test Container Weld Heat Matrix

\begin{tabular}{|c|c|c|c|c|c|}
\hline \multirow[b]{2}{*}{ Weld (Container) } & \multirow[b]{2}{*}{ No. } & \multicolumn{2}{|c|}{ Weld Heat (a) } & \multirow[b]{2}{*}{ Parameter Type } & \multirow[b]{2}{*}{ Burst Pressure } \\
\hline & & $\begin{array}{l}\text { Rotation } \\
\text { (sec/rev) }\end{array}$ & $\begin{array}{l}\text { Current } \\
\text { (A) }\end{array}$ & & \\
\hline 43 Top & & 71 & 49 & Dev Low & 1432 \\
\hline 43 Bottom & & 74 & 54 & Prod Low & \\
\hline 41 Top & & 77 & 60 & Nominal & 1731 \\
\hline 41 Bottom & & 77 & 60 & Nominal & \\
\hline 42 Top & & 80 & 63 & Prod High & 2096 \\
\hline 42 Bottom & & 83 & 68 & Dev High & \\
\hline
\end{tabular}

(a) Development welds done on 4.5-in-diam inner containers.

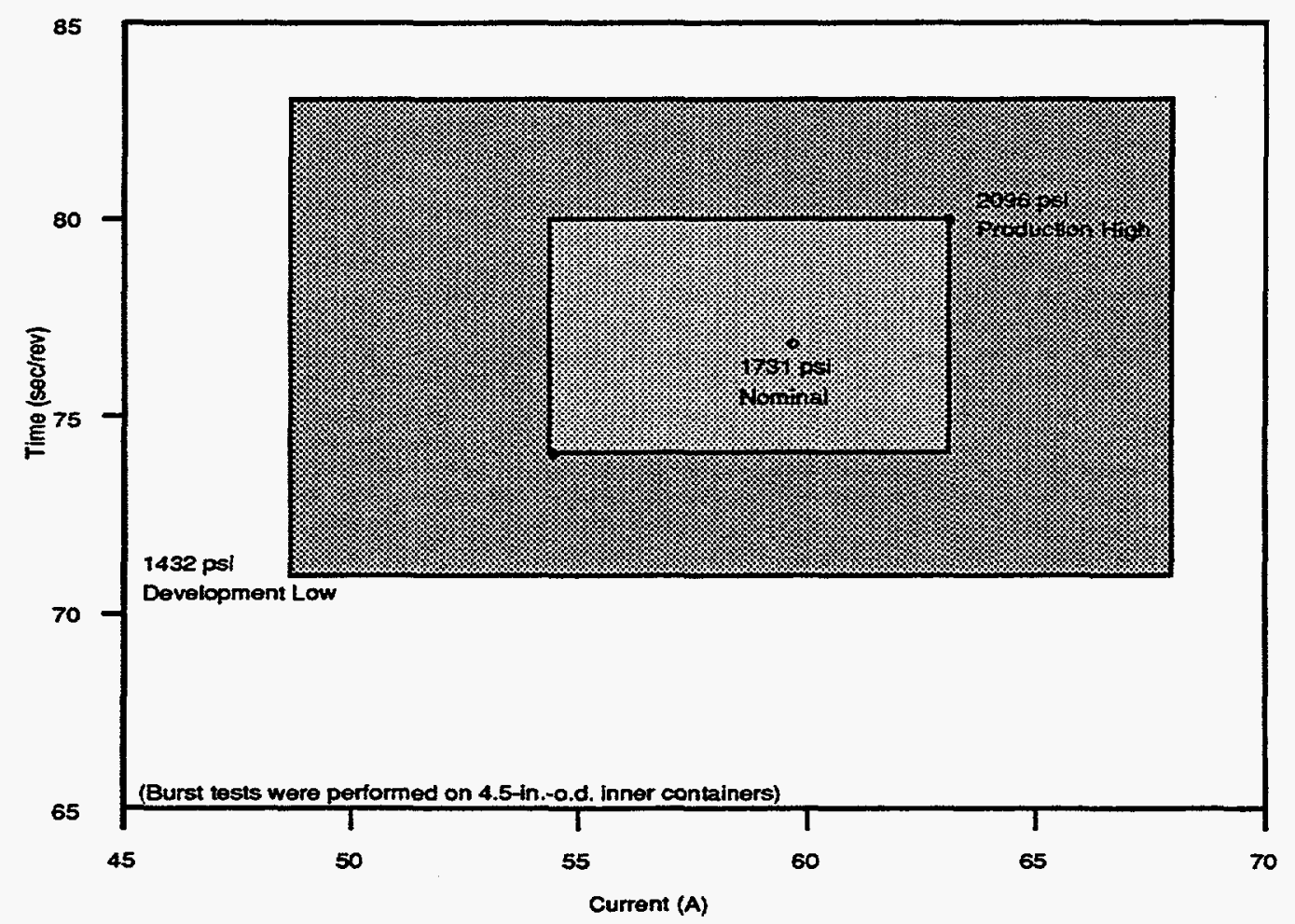

Fig. 12. Container burst strength as a function of weld current and time per rotation settings. 
and the development high weld was intact. One weld on the nominal unit ruptured at $1731 \mathrm{psi}$. For the low unit, the development low weld ruptured at 1432 psi and the production low weld was intact. A full model of burst strength as a function of current and travel speed was not done in this investigation. The full model would require five containers, each container being welded on both ends with the same parameter setting. As shown later however, there are good correlations between current and weld size, and weld size and burst strength.

The typical fracture path observed on the burst containers occurred along the outer weld fusion zone, from the joint centerline to the outside weld toe.

Figures 13-15 show the rupture areas on the three burst containers. Given the fracture path, it seems probable that the burst strength would correlate well with changes in the outer weld reinforcement and fusion zone profile. As mentioned above, however, the outside weld dimension and fusion zone length did not vary appreciably.

Analysis of burst strength as a function of weld size showed a positive linear relationship with both the inside and center weld dimensions. Equations (3) and (4) are the linear models, which are graphically shown in Fig. 16.

$$
\begin{aligned}
& \text { Burst Strength }(\mathrm{psi})=228.0+17007.4 \times \text { Inside Weld Size } \\
& \left(\mathrm{R}^{2}=0.995, \mathrm{RMSE}=26.7\right) \\
& \text { Burst Strength }(\mathrm{psi})=-135.4+23703.2 \times \text { Center Weld Size } \\
& \left(\mathrm{R}^{2}=0.941, \mathrm{RMSE}=113.7\right)
\end{aligned}
$$

The fact that the center weld dimension is tied to burst strength is not unusual since it is a measure of the fusion along the joint interface. The relationship between the inside weld dimension and burst strength, however, is not so apparent. The mechanism by which increased inside weld size improves burst strength may be related to added stiffness imparted by the weld reinforcement 

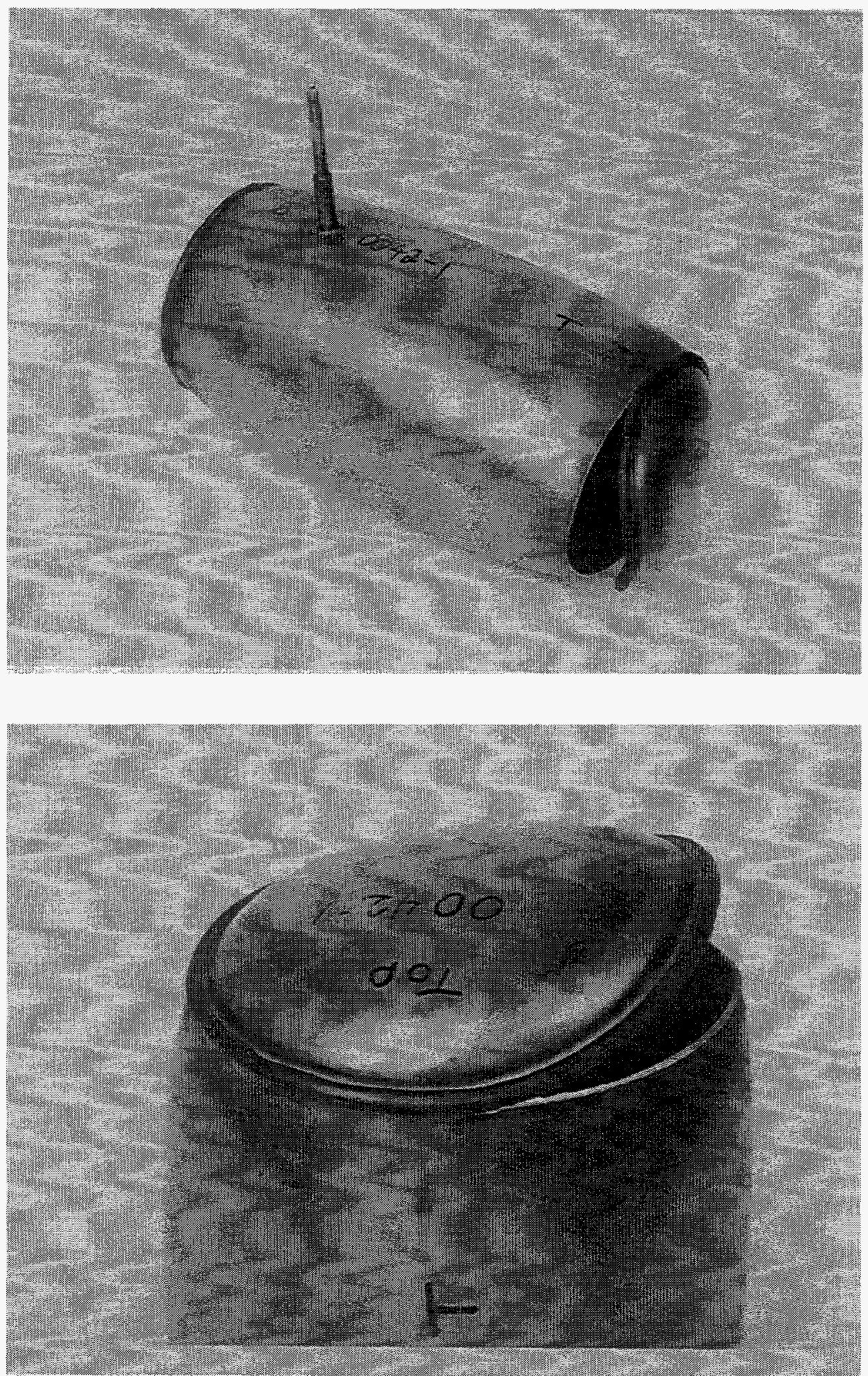

Figs. 13a (above) and 13b. High-heat burst test unit. The production high-heat weld ruptured at 2096 psi, while the development high-heat weld remained intact. 

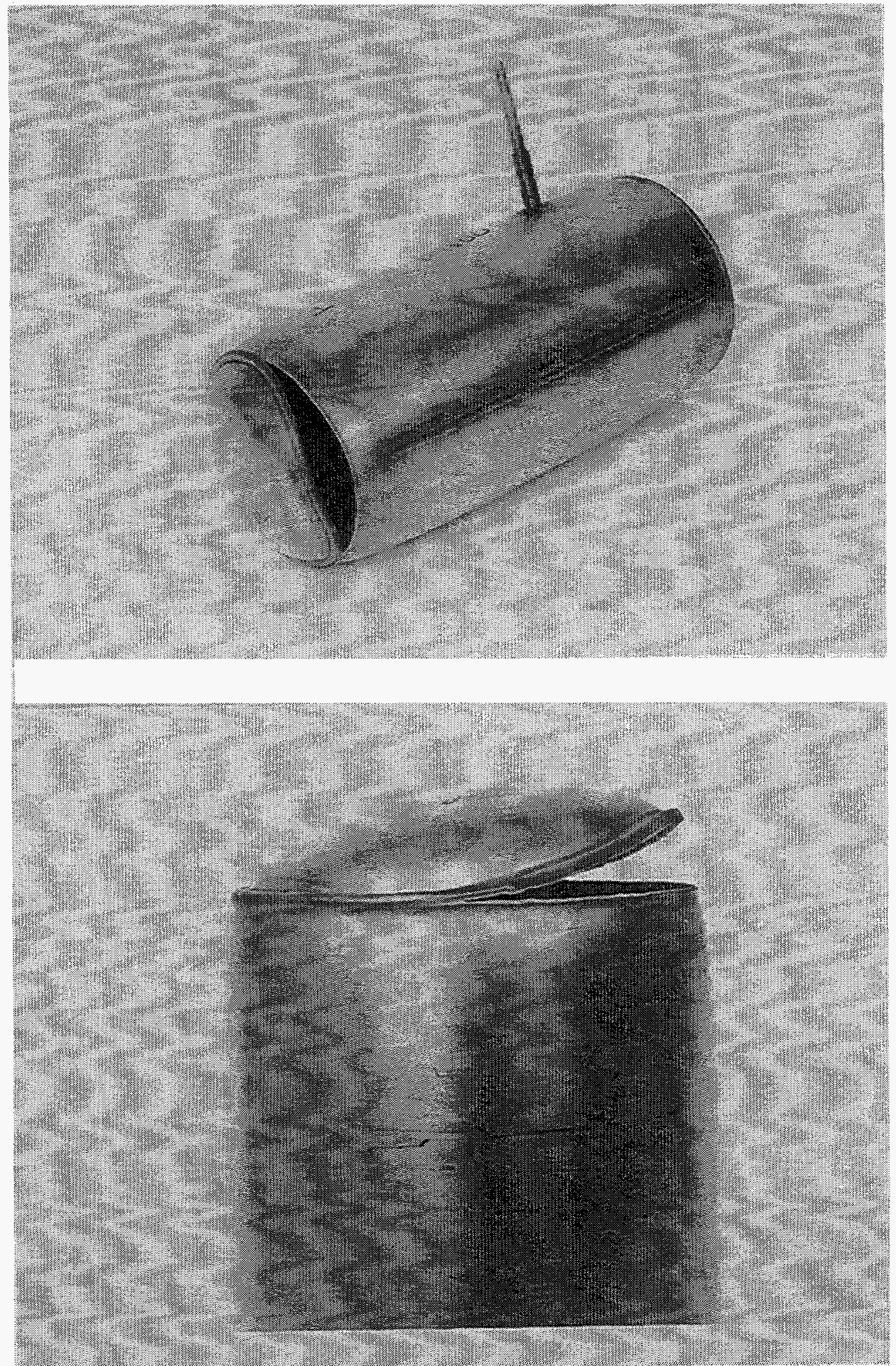

Figs. 14a (above) and 14b. Nominal burst test unit. One nominal weld ruptured at 1731 psi, while the other remained intact. 

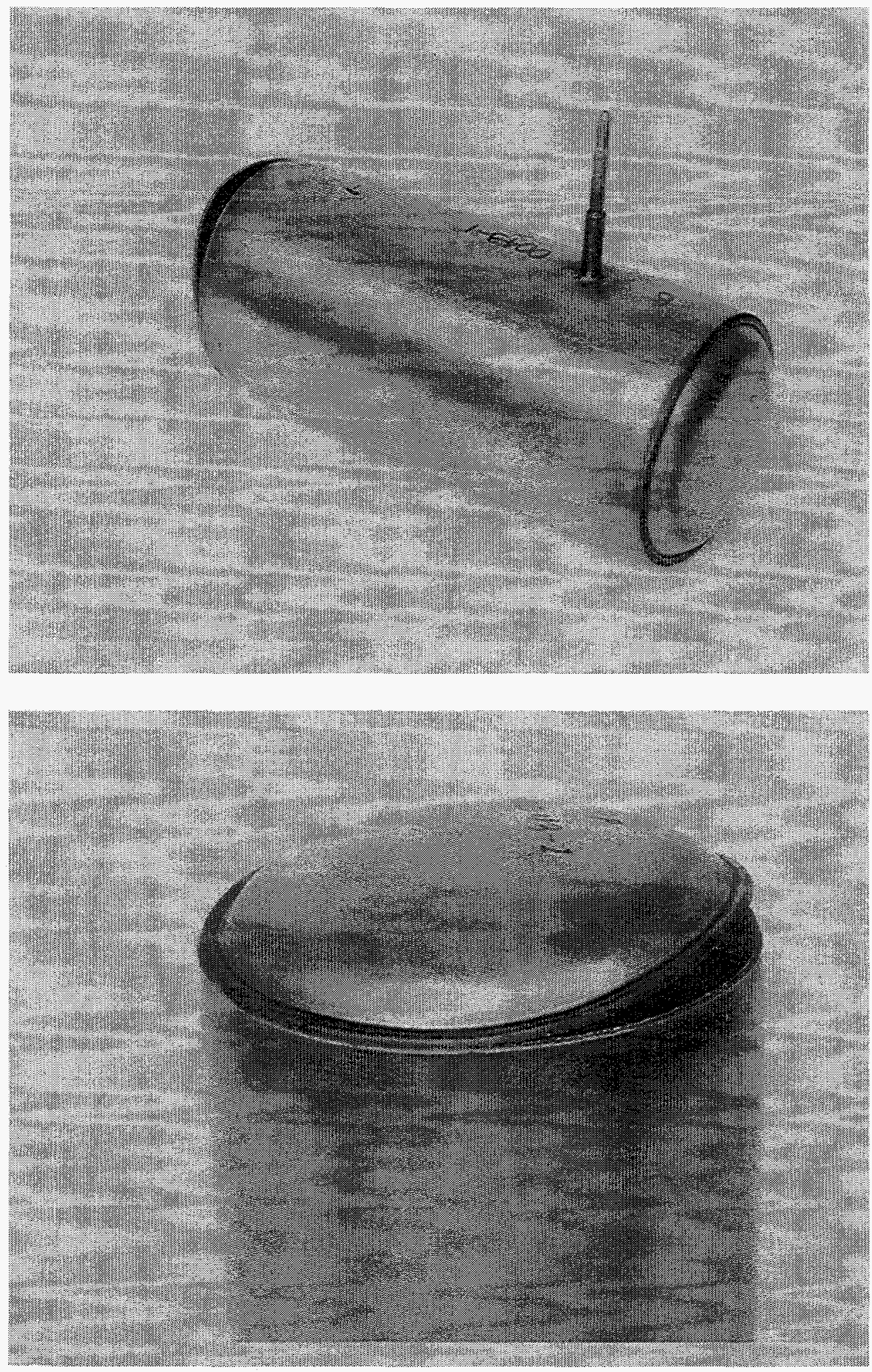

Figs. 15a (above) and 15b. Low-heat burst test unit. The development low-heat weld ruptured at $1432 \mathrm{psi}$, while the production low-heat weld remained intact. 


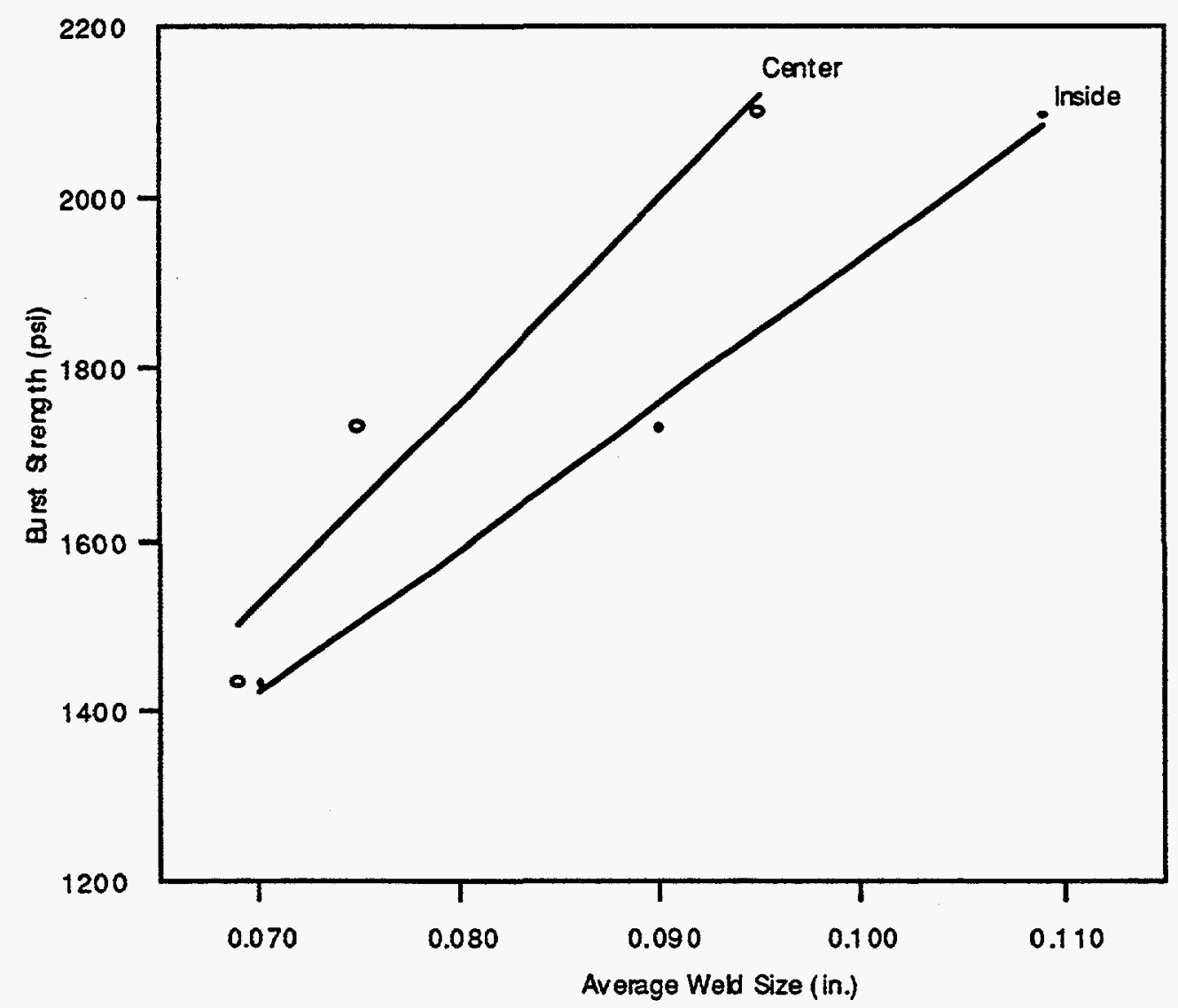

Fig. 16. Burst strength as a function of weld size.

and a resultant increase in the resistance to the deformation of the end piece that is associated with failure. As mentioned earlier, given the fracture path of the burst units, an increase in the outer weld dimension may also increase burst strength.

Because the weld is distorted during burst testing, actual penetration measurements could not be made on the burst-tested containers. The above correlation of weld size and burst strength is based on the assumption that metallographic sample welds done with the same current and travel speed as the burst welds have similar dimensions. This assumption, coupled with the fact 
that there were only three burst tests, requires that these burst strength models be viewed only as trend indicators. Test report TR/BT-95-005 ${ }^{(5)}$ describes the burst testing setup, procedure, and results.

\section{Drop Tests}

The helium leak-test results for the outer container after each drop, and subsequently, for the inner container after the last drop, were acceptable. The measured leak rates were well below the required $1 \times 10^{-7}$ standard $\mathrm{cm}^{3} /$ second. Test report TR/DT-95-005(6) describes the drop testing setup, procedure, and results.

\section{CONCLUSIONS AND RECOMMENDATIONS}

The proof-of-development container welds made in accordance with the procedure 604-NMT4 meet the leak, drop, and burst testing requirements of DOESTD-3013-94. The POD matrix tested conditions of twice the estimated normal process variation for weld current and travel speed. The process was characterized and shows good correlation between the weld current and the resultant weld dimensions and burst strength.

The equipment, fixtures, and procedure require a high degree of attention to detail to ensure proper and consistent setup and thus to produce welds of consistently good quality. To improve weld consistency, predictability, and inspectability as well as container strength, it is suggested that the existing manually controlled welding power supply be replaced with a programmable, microprocessor-controlled system that includes arc pulsing and oscillation features. This equipment will provide greatly improved control and consistency 
of the major welding variables over the present manually operated potentiometer controls. Arc-pulsing and oscillation features potentially provide a means of improving the uniformity of the weld shape in a single-pass, reduced-heat-input process. Weld uniformity and reduced heat input would likely reduce the occurrence of weld microfissures as seen in the high-heat extreme welds and may act to improve burst strength. Another suggested system modification is the redesign of the present torch location system to include multiaxis positioning slides for improved accuracy and repeatability in weld setup.

\section{REFERENCES}

1. "Department of Enengy Standard Criteria for Safe Storage of Plutonium Metals and Oxides," DOE-STD-3013-94, (U.S. DOE, Washington, D.C. 20585, December 1994).

2. Los Alamos National Laboratory Drawing, "Stainless Steel Storage Containers for TA-55 Vault Repackaging," Sheet 1, Inner Container and Lid, Sheet 2, Outer Container and Lid, Number 26Y-203051 (December 1993).

3. Los Alamos National Laboratory Welding Procedure, 604-NMT4-R00, "Fabricating Long Term Storage Containers," (8/9/95).

4. Los Alamos National Laboratory Cleaning Procedure, 600-NMT4-R00, "Cleaning Special Nuclear Material Storage Container Components," $(5 / 12 / 95)$.

5. "Pressure Burst Test Report, Pu Storage Can for NMT-4," Engineering Sciences and Applications Division report TR/BT-95-005, Rev 0, Los Alamos National Laboratory, Los Alamos, N. M. (April 11, 1995). 
6. "Pressure Drop Test Report, PU Storage Can for NMT-4," Engineering Sciences and Applications Division report TR/DT-95-005, Rev 0, Los Alamos National Laboratory, Los Alamos, N. M. (March 29, 1995).

\section{ACKNOWLEDGMENTS}

The authors wish to thank Ramiro Pereyra of CST-15 for metallography in support of weld qualification. Many thanks also to Steve Hopkins of ESA-DE and Richard Harlow of ESA-MT for drop testing and pressure testing, respectively, of the container systems. 


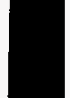
.
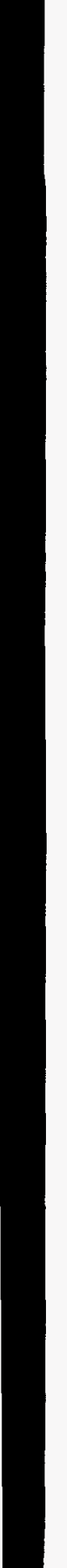

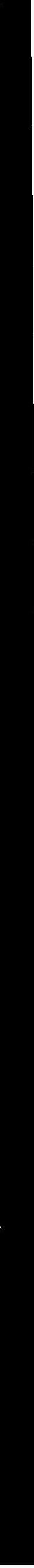

